\title{
Post-glacial reactivation of the Bollnäs fault, central Sweden - a multidisciplinary geophysical investigation
}

\author{
Alireza Malehmir ${ }^{1}$, Magnus Andersson ${ }^{1}$, Suman Mehta $^{1}$, Bojan Brodic ${ }^{1}$, Raymond Munier ${ }^{2}$, Joachim Place $^{1}$, \\ Georgiana Maries $^{1}$, Colby Smith ${ }^{3}$, Jochen Kamm ${ }^{1, a}$, Mehrdad Bastani ${ }^{3}$, Henrik Mikko ${ }^{3}$, and Björn Lund ${ }^{1}$ \\ ${ }^{1}$ Uppsala University, Dept. of Earth Sciences, Uppsala, Sweden \\ ${ }^{2}$ Swedish Nuclear Fuel and Waste Management Company (SKB), Stockholm, Sweden \\ ${ }^{3}$ Geological Survey of Sweden, Uppsala, Sweden \\ ${ }^{a}$ now at: University of Münster, Dept. of Geophysics, Münster, Germany \\ Correspondence to: Alireza Malehmir (alireza.malehmir@geo.uu.se)
}

Received: 10 September 2015 - Published in Solid Earth Discuss.: 15 October 2015

Revised: 22 March 2016 - Accepted: 23 March 2016 - Published: 6 April 2016

\begin{abstract}
Glacially induced intraplate faults are conspicuous in Fennoscandia where they reach trace lengths of up to $155 \mathrm{~km}$ with estimated magnitudes up to 8 for the associated earthquakes. While they are typically found in northern parts of Fennoscandia, there are a number of published accounts claiming their existence further south and even in northern central Europe. This study focuses on a prominent scarp discovered recently in lidar (light detection and ranging) imagery hypothesized to be from a post-glacial fault and located about $250 \mathrm{~km}$ north of Stockholm near the town of Bollnäs. The Bollnäs scarp strikes approximately northsouth for about $12 \mathrm{~km}$. The maximum vertical offset in the sediments across the scarp is $4-5 \mathrm{~m}$ with the western block being elevated relative to the eastern block. To investigate potential displacement in the bedrock and identify structures in it that are related to the scarp, we conducted a multidisciplinary geophysical investigation that included gravity and magnetic measurements, high-resolution seismics, radio-magnetotellurics (RMT), electrical resistivity tomography (ERT) and ground-penetrating radar (GPR). Results of the investigations suggest a zone of low-velocity and highconductivity in the bedrock associated with a magnetic lineament that is offset horizontally about $50 \mathrm{~m}$ to the west of the scarp. The top of the bedrock is found $\sim 10 \mathrm{~m}$ below the surface on the eastern side of the scarp and about $\sim 20 \mathrm{~m}$ below on its western side. This difference is due to the different thicknesses of the overlying sediments accounting for the surface topography, while the bedrock surface is likely to be more or less at the same topographic level on both sides of
\end{abstract}

the scarp; else the difference is not resolvable by the methods used. To explain the difference in the sediment covers, we suggest that the Bollnäs scarp is associated with an earlier deformation zone, within a wide (>150 m), highly fractured, water-bearing zone that became active as a reverse fault after the latest Weichselian deglaciation.

\section{Introduction}

Glacially induced, intraplate faults are conspicuous in northern Fennoscandia (reviewed in Kuivamäki et al., 1998; Lagerbäck and Sundh, 2008; Olesen et al., 2004, 2013; Lund, 2015). While some of them have trace lengths up to $155 \mathrm{~km}$ with estimated magnitudes up to 8 for the associated earthquakes (e.g. Lagerbäck and Sundh, 2008; Arvidsson, 1996; Lindblom et al., 2015), most are shorter or have less surface expression (Fig. 1). Based on the results from a reflection seismic survey, Ahmadi et al. (2015) reported on the Pärvie post-glacial fault in Sweden, which they imaged down to about $8 \mathrm{~km}$ depth (see also Juhlin et al., 2010; Juhlin and Lund, 2011; Lindblom et al., 2015). To the best of our knowledge all known post-glacial faults have been reported to be associated with pre-existing structures (e.g. earlier faults or lithological contacts) that have been reactivated (e.g. MuirWood, 1989; Lagerbäck and Sundh, 2008; Brandes et al., 2012) in a stress regime affected by ice loading and unloading (MuirWood, 1989; Wu et al., 1999; Lund, 2015). Some post-glacial faults appear to be splays of major deforma- 


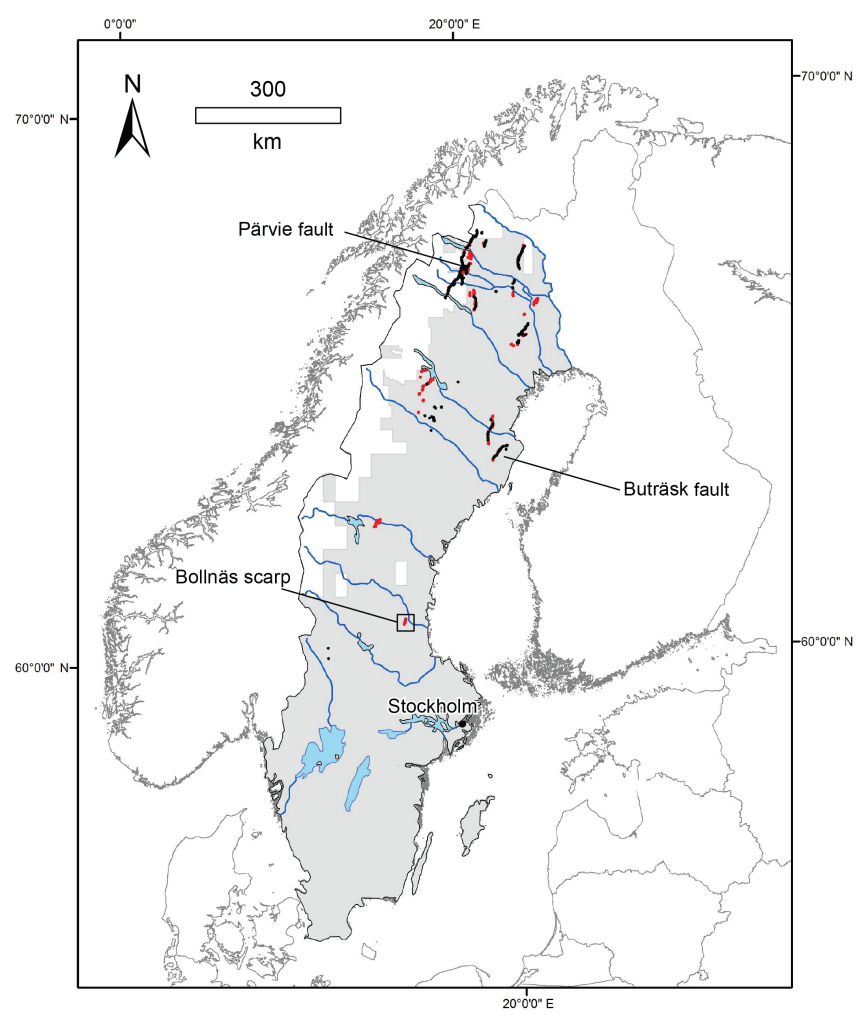

Figure 1. Inferred location of the post-glacial faults in Sweden. Bollnäs prospective fault, being much smaller in size and length, was recently discovered from lidar-imagery data (shaded regions) as a $4-5 \mathrm{~m}$ high scarp. Red dots show the locations of lidar scarps and black dots show known post-glacial faults (e.g. Pärvie and Burträsk).

tion zones while other faults appear to be isolated structures (e.g. Kuivamäki et al., 1998; Dehls et al., 2000; Lagerbäck and Sundh, 2008). Based on lidar-derived imagery, Mikko et al. (2015) suggest that glacially induced faults are not, as previously mapped on aerial photographs, confined solely to the northernmost parts of Sweden but are also found in central Sweden (e.g. Smith et al., 2014). Some of these faults are associated with scarps that strike for more than $12 \mathrm{~km}$, giving a recognizable expression to the lidar-derived imagery. While lidar data provide valuable information, it is important that the presence of the fault is ground truthed, its extent and geometry at depth are unravelled and if possible an estimate of its displacement is given. These, together with the surface expression represented by the scarp, can then provide information about their origin, displacement mechanism(s) and, if applicable, the earthquake magnitude.

The Bollnäs scarp in central Sweden is visible in lidar imagery for ca. $12 \mathrm{~km}$ (Fig. 2a). It was initially interpreted to be about $8 \mathrm{~km}$ long by Smith et al. (2014), however with the aid of studying larger magnetic data (Fig. 2b) in this study, it is possible to extend the fault to $12 \mathrm{~km}$. Smith et al. (2014) suggested that the scarp results from post-glacial faulting because in the lidar imagery it apparently cross-cuts multiple units of glacial and post-glacial sediments (Fig. 3). Although trenching across the scarp to about $3 \mathrm{~m}$ depth showed faulted glacial and post-glacial sediments, the bedrock was not reached. The presence of water-escape structures and an abundance of landslides in the region were interpreted to result from paleo-seismicity associated with fault rupture (Smith et al., 2014). Since this discovery, a few new areas in the central and northern parts of Sweden have been suggested to host small post-glacial faults (Mikko et al., 2015). Although speculative, their presence has also been reported in southern Sweden (Mörner, 2004, 2011; Jakobsson et al., 2014) and northern central Europe (Brandes et al., 2015). These inferred post-glacial faults are infrequently studied using multidisciplinary geophysical methods and remain elusive if associated with structures in the bedrock.

For long-term seismic hazard assessment (important e.g. for nuclear waste storage, water dams and mine-waste tailings) unravelling the geometry and kinematics of glacially induced faults is essential. The Bollnäs scarp was chosen as an appropriate candidate for detailed investigations. A number of geophysical investigations including high-resolution gravity and magnetic measurements, refraction and reflection seismics, ERT, RMT, GPR and differential GPS (DGPS) surveying were carried out. Our objectives were (1) to provide information about the depth to the sediment-bedrock contact on both sides of the scarp, in order to infer potential bedrock displacement and potential related earthquake magnitude, (2) to determine if the scarp was associated with any clear structure within the bedrock and (3) to provide plausible scenarios that can explain how the scarp was formed.

\section{Geological background}

Smith et al. (2014) provided a detailed description of the post-glacial depositional environment of the Bollnäs area. For completeness, a short summary of their findings is provided here. The bedrock (Fig. 3) is dominantly metagranite and gneiss of Svecokarelian age (1.97-1.87 Ga; Sukotjo and Sträng, 2005; Albrecht and Kübler, 2011). At least two sets of tills are present in the study area. The uppermost till dates to the retreat of the late Weichselian Fennoscandian ice sheet, which retreated across this part of Sweden about 11000 years ago. Varved clays, deposited in a freshwater lake in the Baltic basin (Björck, 1995), overlie the uppermost till. Above the varved sediments lie massive deposits of clay, often grading into silt or fine sand deposited during the regression of Baltic waters.

The Bollnäs scarp is associated with a north-south topographic lineament, striking nearly $12 \mathrm{~km}$ long,located about $2.5 \mathrm{~km}$ west of the city of Bollnäs (Fig. 1). The scarp was first suggested to be ca. $8 \mathrm{~km}$ long (Smith et al., 2014) but with the help of large-scale airborne magnetic data and enhancement of magnetic lineaments (Fig. 2b) we found additional seg- 

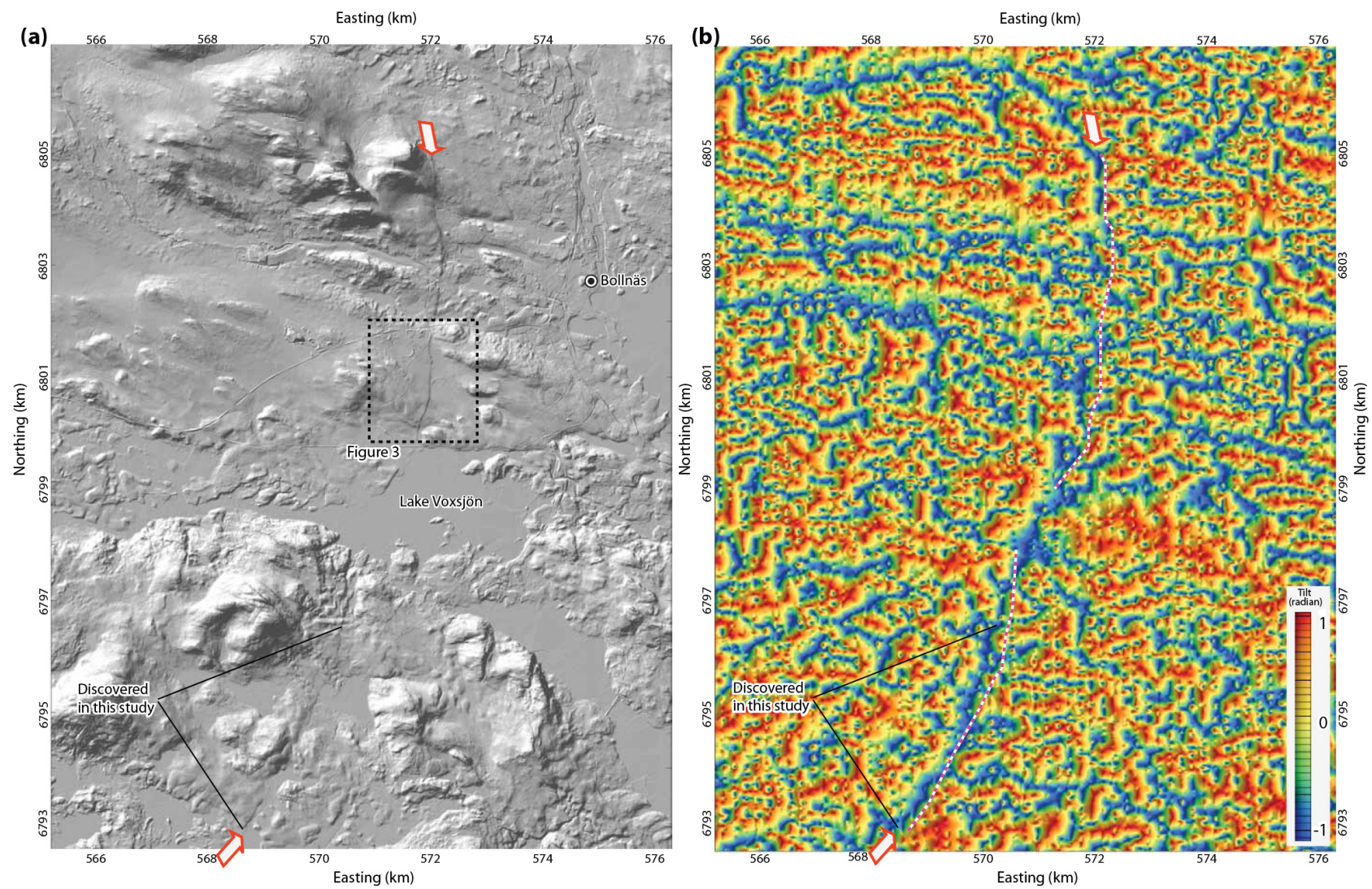

Figure 2. (a) Shaded relief lidar map and (b) tilt-derivative (shown as radian angle) of total-field aeromagnetic map showing the Bollnäs scarp and noticeable magnetic lineament (with an offset of about $40 \mathrm{~m}$ ) associated with it. The scarp occurs slightly east of the magnetic lineament, following it for about $12 \mathrm{~km}$. Lidar data were provided by Lantmäteriet and magnetic data by the Geological Survey of Sweden.

ments, also in the lidar data, in the southern parts (Fig. 2a). To enhance the magnetic signature of the fault, we used the tilt derivative approach introduced by Miller and Singh (1994). The title angle (in radian) is essentially obtained using the inverse tangent of the ratio of first vertical and total horizontal derivatives.

Our DGPS elevation measurements across the scarp show a $\sim 4-5 \mathrm{~m}$ difference in the topography across the scarp (Fig. 3), in agreement with the data collected by Smith et al. (2014). Based on the field observations, the scarp crosscuts surficial sediments including till, glaciofluvial sediments and glacial clay (Smith et al., 2014), suggesting that it is likely to be associated with post-glacial faulting; not from the synglacial periods as suggested, for example, for the Pärvie fault in northern Sweden (e.g. Lagerbäck and Sundh, 2008). No outcrops of basement rocks are found in the vicinity of the scarp, hence no fault or fault plane and sense of movement can be directly associated with the scarp. However, most glacially induced faults appear to be dominantly reverse, dipping between 50 and $60^{\circ}$ (Juhlin et al., 2010; Juhlin and Lund, 2011; Ahmadi et al., 2015) and associated with zones of weakness in the bedrock (e.g. shear zones or at rock contacts). Prior to this study, existing water well data in the study area were obtained from the database of the Geological Survey of Sweden (SGU; Fig. 3b). Well data are limited in the study area and are ambiguous, with one well suggesting that surficial sediments are thicker on the western side of the scarp.

In terms of seismicity, except for a recent (year 2014) magnitude 4 earthquake that occurred about $100 \mathrm{~km}$ west of Bollnäs, the Swedish National Seismic Network (SNSN, 2015; see also Bödvarsson and Lund, 2003) only reports very minor seismic activity in the area. Since the establishment of the modernized SNSN in the region in 2000, 36 microearthquakes with magnitudes in the range -0.2 to 1.4 have been recorded within $15 \mathrm{~km}$ of the scarp. These events do not define a linear structure, as micro-earthquakes on the postglacial faults in northern Fennoscandia tend to (Lindblom et al., 2015), and most of the events near Bollnäs seem unrelated to the scarp.

\section{Methods}

Several geophysical surveys were conducted during October 2014 in one of the areas already investigated by Smith et 
a)

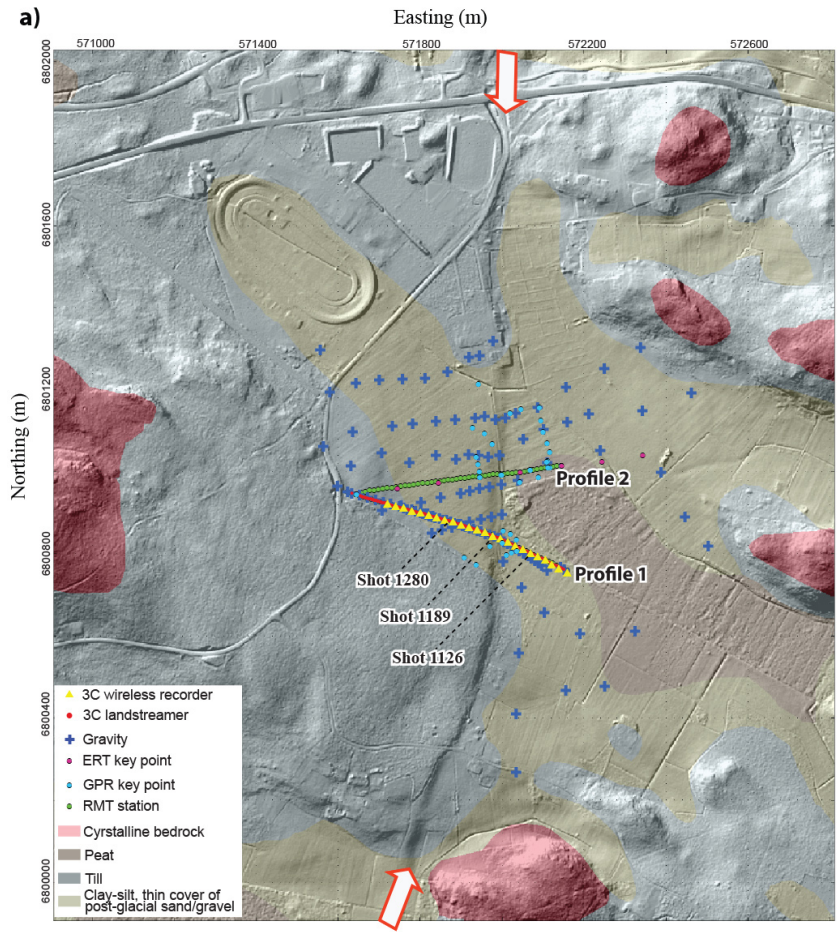

b)

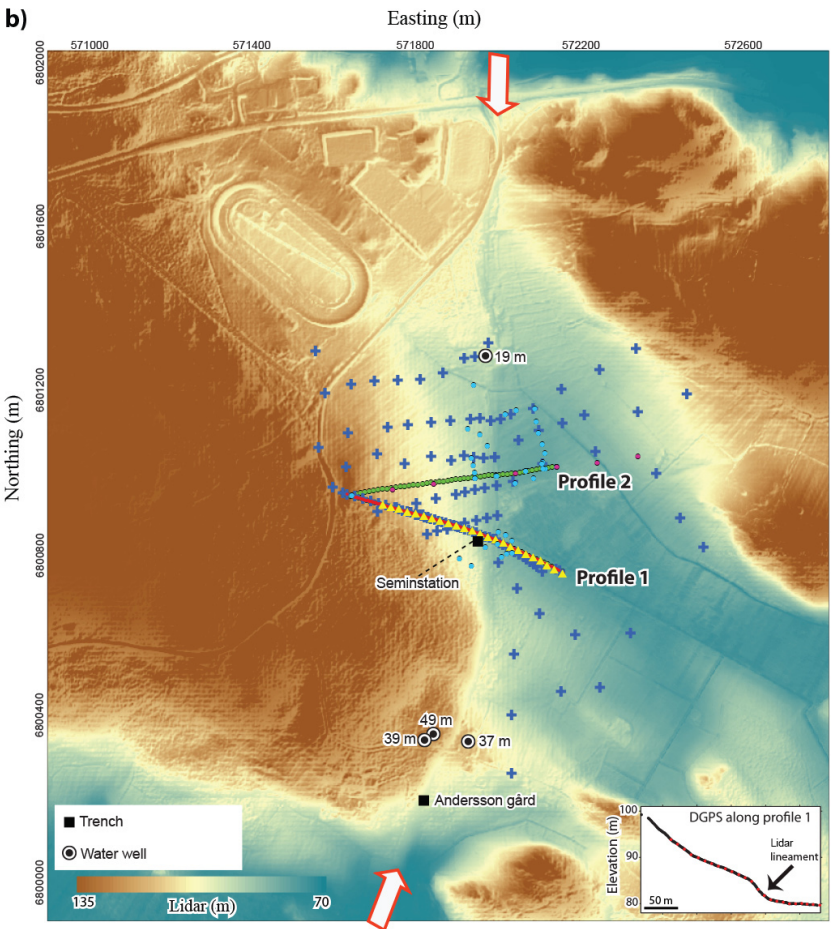

Figure 3. (a) Surface geological map (Courtesy of the Geological Survey of Sweden) of the Bollnäs area projected onto hill-shaded lidar topographic data (Courtesy of Lantmäteriet) showing a clear scarp that is on average $5 \mathrm{~m}$ higher on the western than its eastern sides. Earlier studies based on results from shallow trenching (e.g. Smith et al., 2014) suggested a possibility for a post-glacial fault associated with the scarp. (b) Lidar data (no shading) showing the location of the scarp relative to where the geophysical data presented in this study were acquired. Seismic data were only acquired along profile 1. Our DGPS-elevation measurements along profile 1 are shown as an inset figure in (b). Various symbols (see the legend) show the locations of the geophysical measurements presented in this study. Numbers in (b) show bedrock depth as reported from the water wells in the study area.

al. (2014). Two profiles perpendicularly crossing the scarp were planned after a detailed reconnaissance prior to the surveys. While most investigations were carried out along these two profiles (Fig. 3), the focus was given to profile 1, where refraction and reflection seismic data were collected. Table 1 provides details of the acquisition parameters for the different methods. Figure 4 shows a collection of field photos from different methods used in this study. Below, we briefly describe the methods, their basis and what we measured in the study area.

\subsection{Gravity and magnetic measurements}

Gravity and ground magnetic measurements (Fig. 4b, d) were carried out using a LaCoste and Romberg ${ }^{\mathrm{TM}}$ model G gravity meter and a $\mathrm{GEM}^{\mathrm{TM}}$ magnetometer (data handling was done using routine algorithms implemented in Oasis Montaj ${ }^{\mathrm{TM}}$ ). Gravity data were collected at every $10 \mathrm{~m}$ along profile 1 (53 points) and in scattered locations around the profile (Fig. 3) in order to provide a good indication of the possible depth to the bedrock in the area and to correlate with other measurements. The gravimeter is equipped with electronic levels and beam indicators. A base station in a calm location in the study area was chosen to correct the instrument drift; the base station was surveyed at the beginning and end of each day of surveying. Linear regression of the base station readings provided an estimate of the instrument drift being $0.001 \mathrm{mGal} \mathrm{h}^{-1}$. Typical tidal variations for a day of surveying in the area during the measurement times were calculated to be on the order of 0.4 to $0.6 \mathrm{mGal}$. Based on the repeated measurements at the base station a standard deviation of $0.06 \mathrm{mGal}$ was obtained, implying a high reliability of the gravimeter for this survey. All gravity points (128 data points) were surveyed accurately (less than $3 \mathrm{~cm}$ error for the elevation) using a DGPS geodetic surveying instrument. Our estimation of the total error, assuming this can be represented by summing all the errors (or standard deviations) of the equipment error $(0.6 \mathrm{mGal})$, DGPS elevation error (free-air corrections, $0.1 \mathrm{mGal}$ ), latitude corrections (negligible given the high accuracy of the DGPS system), Bouguer corrections $(0.1 \mathrm{mGal})$ and terrain corrections (maximum $0.2 \mathrm{mGal}$ ), is about $0.8 \mathrm{mGal}$. We estimated the error for the Bouguer correction by subtracting the Bouguer values from two successive densities tested in this study (e.g. 2000 and $2050 \mathrm{~kg} \mathrm{~m}^{-3}$ ) and calculating its standard deviation. 
Table 1. Summary of some the acquisition parameters, October 2014.

\begin{tabular}{|c|c|c|c|c|}
\hline Survey type & Seismic & ERT & RMT & Gravity and magnetic \\
\hline Acquisition system & SERCEL Lite 428 & $\mathrm{ABEM}^{\mathrm{TM}}$ & EnviroMT & Lacoste and Romberg and GEM ${ }^{\mathrm{TM}}$ \\
\hline No. of receivers & $\begin{array}{l}\text { 80-3C landstreamer, } 12-3 \mathrm{C} \\
\text { plant and } 24-3 \mathrm{C} \text { wireless }\end{array}$ & 48 & 5 (2 E-field and 3 Mag-field) & $\begin{array}{l}128 \text { gravity points and } 22153 \\
\text { magnetic points }\end{array}$ \\
\hline No. of source points & 256 & - & Up to 20 transmitters & - \\
\hline Receiver interval & $\begin{array}{l}2-4 \mathrm{~m} \text { (streamer) and } 20 \mathrm{~m} \\
\text { wireless recorders }\end{array}$ & $2-4 \mathrm{~m}$ & $10 \mathrm{~m}$ & $\begin{array}{l}10 \mathrm{~m} \text { (gravity) and } \\
1-2 \mathrm{~m} \text { (magnetic) }\end{array}$ \\
\hline Shot interval & $10 \mathrm{~m}$ & $4 \mathrm{~m}$ & - & - \\
\hline Source-receiver offset & $480 \mathrm{~m}$ & - & - & - \\
\hline Source size & Bobcat $300 \mathrm{~kg}$ drop hammer & - & Passive $(14-250 \mathrm{kHz})$ & - \\
\hline Profile length & $600 \mathrm{~m}(\mathrm{P} 1)$ & $\begin{array}{l}400 \mathrm{~m}(\mathrm{P} 1) \text { and } \\
720 \mathrm{~m}(\mathrm{P} 2)\end{array}$ & $560 \mathrm{~m}(\mathrm{P} 1)$ and $490 \mathrm{~m}(\mathrm{P} 2)$ & $\begin{array}{l}600 \mathrm{~m}(\mathrm{P} 1) \text { and } 500 \mathrm{~m}(\mathrm{P} 2) \\
\text { also at scattered locations }\end{array}$ \\
\hline \multicolumn{5}{|l|}{ Spread } \\
\hline Record length & $10 \mathrm{~s}$ (1 s used) & - & 50 times power stacking & - \\
\hline Sampling rate & $1 \mathrm{~ms}$ & - & $2 \mathrm{MHz}$ & Walking mode (magnetic) \\
\hline Sensor & 3C-MEMs & 48 & Electric and magnetic fields & $\begin{array}{l}\text { Vertical (gravity) and total-field } \\
\text { (magnetic) }\end{array}$ \\
\hline No. of sensors & Single & Multiple & $\begin{array}{l}\text { Two horizontal E-field and } \\
\text { two horizontal and one vertical } \\
\text { magnetic }\end{array}$ & - \\
\hline Pattern & 3 impacts/point & Gradient array & Vertical electrical dipoles & - \\
\hline
\end{tabular}

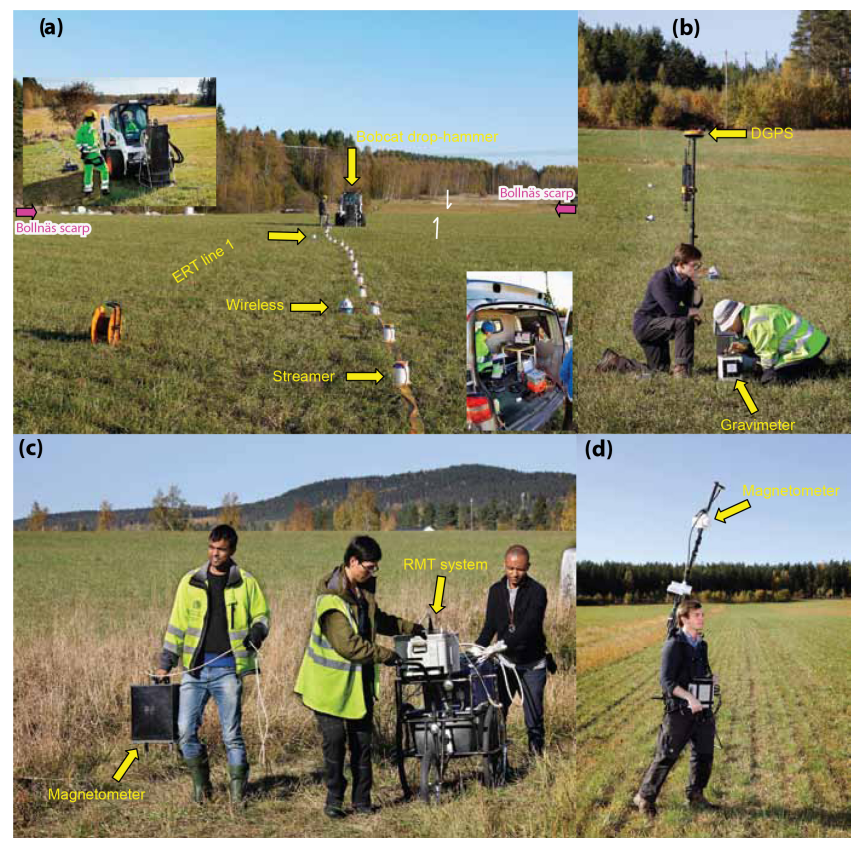

Figure 4. Field photos showing (a) the seismic data acquisition using combined wireless (24-fixed, $20 \mathrm{~m}$ spacing) and cabled (92-MEMs-based streamer and planted, 2-4 m spacing) seismic recorders and Bobcat-mounted drop hammer as the seismic source. Panel (b) shows gravity (128 points were measured) and geodetic surveying, (c) shows RMT data acquisition (10 m spacing along profiles 1 and 2) and (d) shows the total-field magnetic surveying. The geophysical data acquisition took six days in total in two separate field campaigns during October 2014. The Bollnäs scarp and its apparent displacement are visible in (a; see the half arrows).
Figure 5a shows the free-air gravity map of the study area, which as expected follows the surface topography of the study area. In order to obtain a reasonable density for the Bouguer corrections and minimize effects of the topography in the results and interpretations, we carried out an analysis of the Bouguer corrections based on various densities (50 $\mathrm{kg} \mathrm{m}^{-3}$ increments; Fig. 6a) and checked if there was correlation with the topography (Reynolds, 2011). Based on this analysis (Fig. 6b), we chose $2000 \mathrm{~kg} \mathrm{~m}^{-3}$ density (least correlation coefficient) for the Bouguer corrections. To obtain a complete Bouguer correction then we applied terrain corrections following Kane (1962). Figure $5 \mathrm{~b}$ shows the complete Bouguer-corrected (using $2000 \mathrm{~kg} \mathrm{~m}^{-3}$ ) gravity map of the study area from the measurements. It is clear that there are only minor gravity variations across the scarp along profile 1. However, in general, values are higher on the eastern side than on the western side (only about $1 \mathrm{mGal}$ ). This will be discussed later.

Magnetic data, both total field and vertical gradient, were collected at 22153 points using a walking mode (GPSmounted) method. A base station was placed away from the survey area in a calm place and used to correct the diurnal and instrument drift. Inspection of the vertical gradient data suggested no useful information for our purposes and thus the data were excluded from the interpretations. However, total-field magnetic data show (Fig. 5c) a clear change in the magnetic properties on different sides of the scarp. The difference is on the order of $200 \mathrm{nT}$. Using the world magnetic model of October 2014 (http://www.ngdc. noaa.gov/geomag-web/), the earth's magnetic field intensity, inclination and declination in the study area were around $51460 \mathrm{nT}, 73$ and $5^{\circ}$ respectively. No attempt was made to 

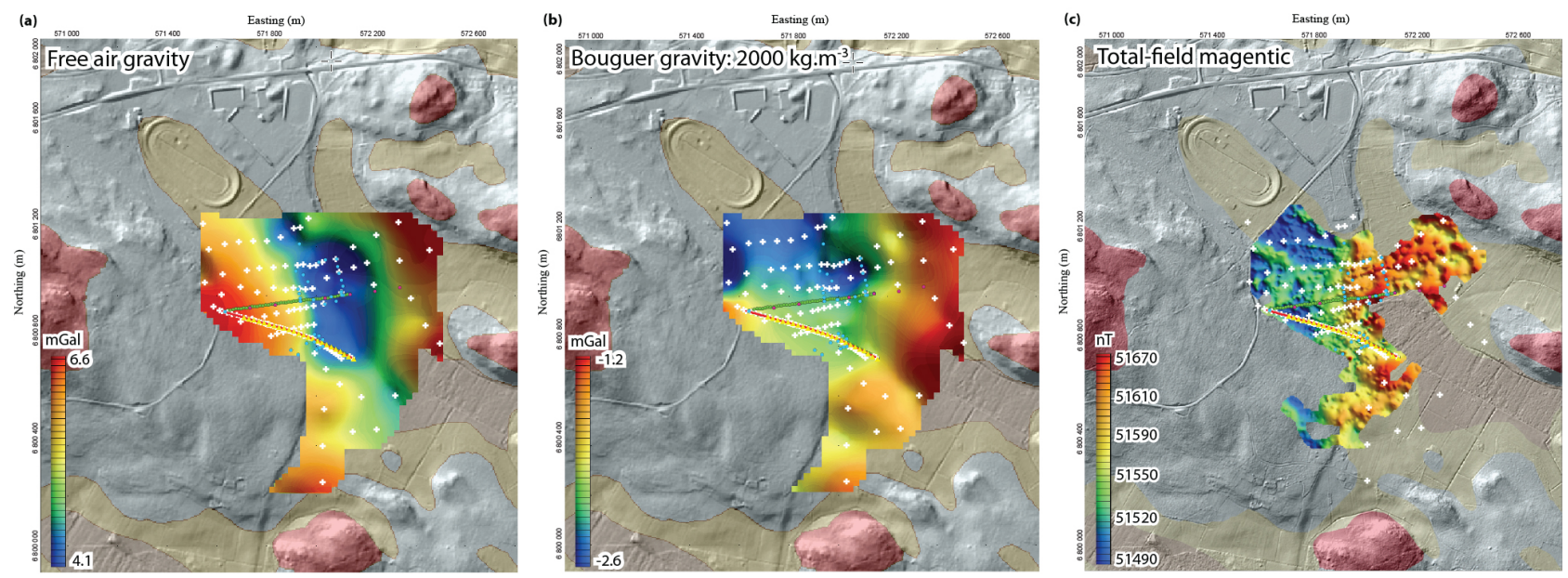

Figure 5. (a) Free-air gravity map, (b) complete Bouguer gravity map (corrected using a density of $2000 \mathrm{~kg} \mathrm{~m}^{-3}$; see also Fig. 6) accounting for the sediments forming the topography and (c) total-field magnetic map of the study area. A clear indication of magnetic high on the eastern side of the scarp is noticeable whereas this is absent along profile 1, but partly evident on the northern side of the gravity-surveyed area. Magnetic data clearly suggest a lineament about $50 \mathrm{~m}$ west of the scarp.

obtain a magnetic anomaly (through, for example, IGRF removal or low-order polynomial approaches) from the totalfield magnetic values given the small surveyed area.

The gravity and magnetic measurements were conducted in two field campaigns (three days each) to cover a much larger area than the other data sets and after observing interesting results in the first field campaign. The measurements were initially bound to the two profiles, but later expanded to cover areas in the south and north of the profiles (Figs. 3 and 4).

\subsection{Seismic survey}

The refraction and reflection seismic study was carried out using a combination of a recently developed MEM-based (micro electro-mechanical system) 3C landstreamer (Fig. 4a; Malehmir et al., 2015a, b; Brodic et al., 2015) and 24 wireless recorders (UNITE connected to 3C-MEM sensors). First, wireless recorders were deployed at every $20 \mathrm{~m}$ along profile 1 . Then a streamer (four segments in total $200 \mathrm{~m}$ long and consisting of $803 \mathrm{C}$-MEM sensors) was used to acquire the seismic data from the south-east to the north-west. In addition to the landstreamer and wireless recorders, 12 3CMEMs sensors ( $2 \mathrm{~m}$ apart) were planted at the tail of the streamer to provide slightly higher fold and offset coverage. In one segment of the landstreamer, used on the tail of the profile when moving, the sensor spacing was $4 \mathrm{~m}$, while in the other three segments it was $2 \mathrm{~m}$. In total, the streamer had to be moved four times to cover profile 1, resulting in a total of 275 receiver positions. Given that the position of the wireless recorders was fixed during the survey, a maximum offset of about $480 \mathrm{~m}$ was achieved. A SERCEL LITE ${ }^{\mathrm{TM}}$ recording system was used for the data acquisition. The data sampling and time stamping were done using a built-in GPS system, allowing the wireless data operating in a passive mode (continuous recording) to be harvested using the GPS times of the streamer (cabled) data. Shooting was only carried out near the streamer sensor positions.

To generate the seismic signal, we used a $300 \mathrm{~kg}$ drop hammer mounted on a Bobcat (Fig. 4a; Place et al., 2015). At every shot position, three source records were generated and stacked vertically to increase the signal-to-noise ratio. In total, 256 shot positions and 29696 seismic traces were generated. Seismic data and, in particular, first breaks have high quality, which allowed them to be used for refraction tomography purposes. No clear reflections could be observed in the data. Thus, neither reflection data processing nor multicomponent processing was carried out. Figure 7 shows three example shot gathers (after being vertically stacked for the repeated shot records) from the eastern, central and western sides of the scarp. A careful inspection of the direct and refracted arrivals clearly suggests a deeper refractor (likely from the bedrock) on the western side of the scarp than on its eastern side. We later show all first breaks as picked to provide a better comparison with the velocity model obtained from these data.

After vertically stacking for the repeated source records, the combined streamer and wireless data sets were used for first break picking. Nearly 27800 first breaks were automatically picked (at their first energy onset), and then a careful inspection and manual correction were performed where required. Our analysis of the reciprocal times suggests an average error of nearly $2 \mathrm{~m} \mathrm{~s}^{-1}$ for the first break picks. We used a $1 \mathrm{~m} \mathrm{~s}^{-1}$ sampling rate for the data acquisition. Figure $8 \mathrm{a}$ shows all travel time picks as a function of offsets. 

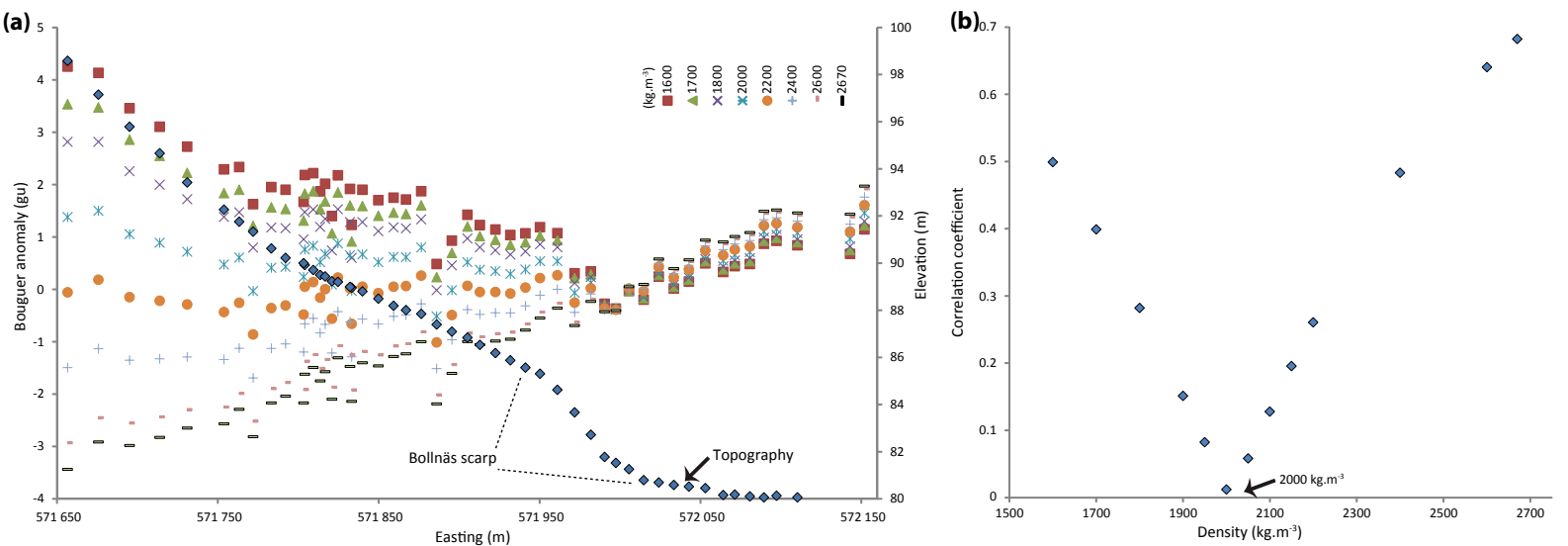

Figure 6. Estimation of density for Bouguer correction (slab correction) using an approach based on the correlation with the topography. (a) Bouguer-corrected gravity data (shown based on gravity unit) along profile 1 using various densities and (b) their correlation coefficient (absolute value) calculated against the topography. This suggests that a density of $2000 \mathrm{~kg} \mathrm{~m}^{-3}$ can represent the cover materials for the slab/Bouguer correction.
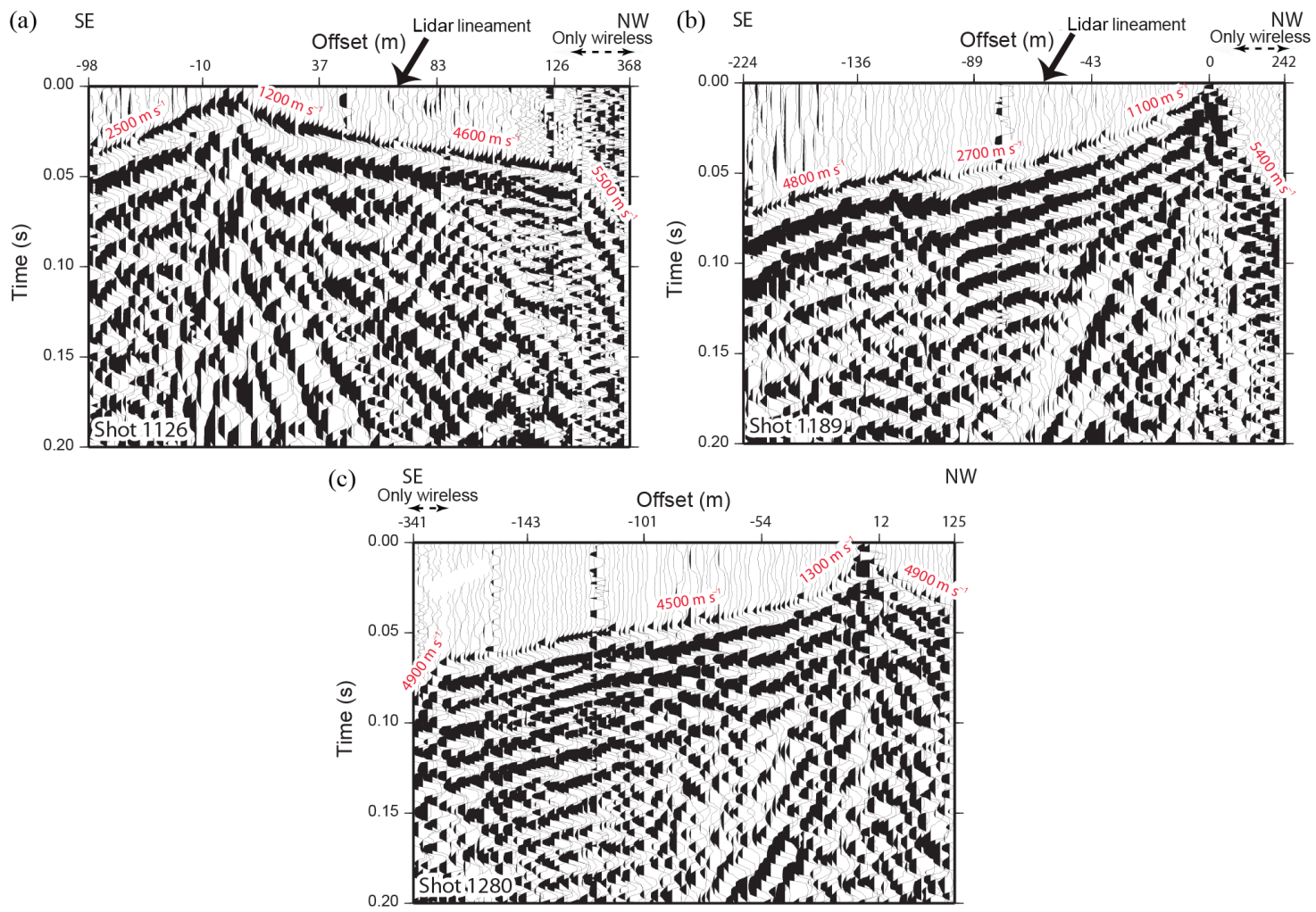

Figure 7. Example shot gathers from (a) eastern, (b) central and (c) western parts of profile 1 (also scarp) showing the quality of the seismic data particularly first breaks and an indication of deeper bedrock in the western side of the scarp. The central shot suggests an apparent low velocity zone $\left(2700 \mathrm{~m} \mathrm{~s}^{-1}\right)$. Note that the far-offset data are from wireless recorders that are about $20 \mathrm{~m}$ apart.

Both refraction data analyses (e.g. generalized linear inversion 2-D ray-tracing method; Palmer, 2010) and first break tomography were performed. Refraction data analysis, in general, showed similar structures to the tomography results, but it was not convincing, likely due to possible 3-D effects, strong vertical velocity gradients and/or strong velocity lateral variations that cannot be accounted for by conventional refraction approaches.

Refraction tomography was carried out using the 3-D PStomo_eq code (Benz et al., 1996; Tryggvason et al., 2002; 
(a)
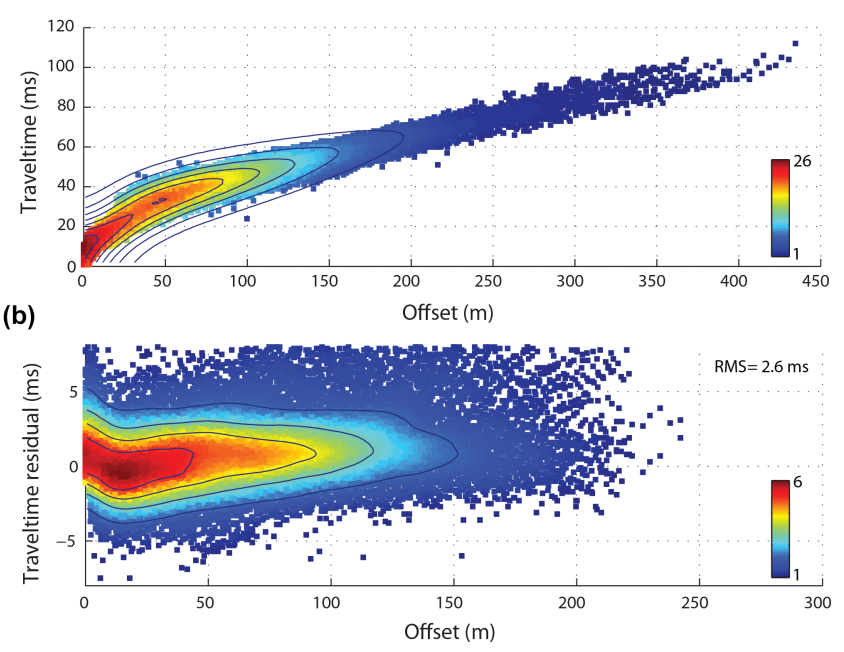

Figure 8. (a) All first break picks as a function of offset (colourcoded and contoured based on the data density). (b) The travel time residuals (observed minus calculated travel times) as a function of offset for all the receiver locations obtained in the last inversion iteration. An RMS of $2.6 \mathrm{~m} \mathrm{~s}$ was obtained. Note that high RMS picks were discarded during the inversion, resulting in smaller offsets in the final inversion than those that were picked.

Tryggvason and Bergman, 2006). The tomography code works in 3-D. Careful discretization is required in 3-D space to provide a reasonable velocity model of the subsurface. PStomo_eq uses a 2-D (or 1-D) starting model and a builtin forward solver that computes travel times for all shots and receive pairs (Hole, 1992; Podvin and Lecomte, 1991; Hole and Zelt, 1995). Backward propagation from the receiver location to the source location is then done perpendicular to the isochrones (Hole, 1992) using ray tracing methods.

Based on a number of tests and our earlier studies using similar equipment and field set-up (Malehmir et al., 2015a, b), we chose model cell sizes of $2 \mathrm{~m}$ horizontal inline, $30 \mathrm{~m}$ horizontal crossline and $1 \mathrm{~m}$ vertical. This discretization was chosen so that most of the rays only cross the cells in the middle of the 3-D velocity model, hence allowing the results to be presented by a 2-D section using a slice from the 3-D velocity volume.

Eight iterations were performed and an RMS misfit of $2.6 \mathrm{~m} \mathrm{~s}$ was obtained for the final velocity model. Figure $8 \mathrm{~b}$ shows the travel time residuals (observed minus predicted travel times) as a function of offset for all the receiver locations. Far-offset data typically show higher misfit because they depend on both shallow and deeper velocities. Shallow velocities are then constrained mainly by the high-density ray coverage of the near-offset first breaks, influencing a deeper and more limited ray coverage of the far-offset first breaks.

\subsection{RMT and ERT surveys}

The RMT method uses distant radio-transmitters (15$250 \mathrm{kHz}$ ) as EM sources and by measuring two components of the electric field and three components of the magnetic field, it is possible to derive the resistivity structure of the subsurface (Bastani, 2001; Pedersen et al., 2006). There have been several published accounts illustrating the success of the method in resolving near-surface geological structures (e.g. Bastani et al., 2009, 2011; Shan et al., 2014). The EnviroMT equipment of Uppsala University (Fig. 4c; Bastani, 2001) was used for the RMT data acquisition. On average, 20 different frequencies could be utilized for the measurements, ranging from 15 to $250 \mathrm{kHz}$. The measurements were carried out every $10 \mathrm{~m}$ along profiles 1 (56 stations) and 2 (49 stations). For details of RMT measurements and the underlying principals, readers are referred to Bastani (2001). Figure $9 \mathrm{a}, \mathrm{b}$ shows examples of apparent resistivity and phase data recorded for the stations along profile 1 . The data quality ranges from good to very good and it is already possible to derive a crude interpretation of the resistivity structures from the raw data.

To derive resistivity models along profiles 1 and 2, we inverted the determinant response of the RMT data using EMILIA (Kalscheuer et al., 2008), which is a modified version of the REBOCC programme (Siripunvaraporn and Egbert, 2000). Inverting determinant data is recommended because the determinant data are rotationally invariant and also because it smoothens out 3-D effects in the 2-D inversion (Pedersen and Engels, 2005). The programme is based on a finite difference technique and hence an optimal mesh design is an important factor to be considered. To set up the model, we used $1 \mathrm{~m}$ cells at the top of the model that increase vertically with a geometrical progression of 1.12 down to $1200 \mathrm{~m}$ depth (only the first $100 \mathrm{~m}$ are of interest in our case). The horizontal cells were fixed as two blocks per measuring point i.e. $5 \mathrm{~m}$. A starting model of homogeneous half space with $1000 \mathrm{Ohm} \mathrm{m}^{-1}$ and Occam-type regularization was used. With an error floor of $4 \%$ on apparent resistivity and phase $\left(1.2^{\circ}\right)$, resistivity models with an average RMS error of about 2.8 were obtained for both profiles.

Figure $9 \mathrm{c}, \mathrm{d}$ shows the estimated apparent resistivity and phase for the data along profile 1 and Fig. 9e, f shows their corresponding misfit (normalized) with the observed data. The normalization is based on e.g. Bastani et al., (2011) where the difference between observed and estimated is divided by the estimated data error at each frequency and station.

ERT is a fast and relatively inexpensive geophysical method commonly used for near surface applications (Stummer et al., 2004; Günther and Rücker, 2006a, b: Paasche, 2006; Loke, 2014; Reynold, 2011; Shan et al., 2014). The method is designed for detecting differences in resistivity of the subsurface materials. In contrast to the RMT method, which is primarily sensitive to conductive structures, ERT is 

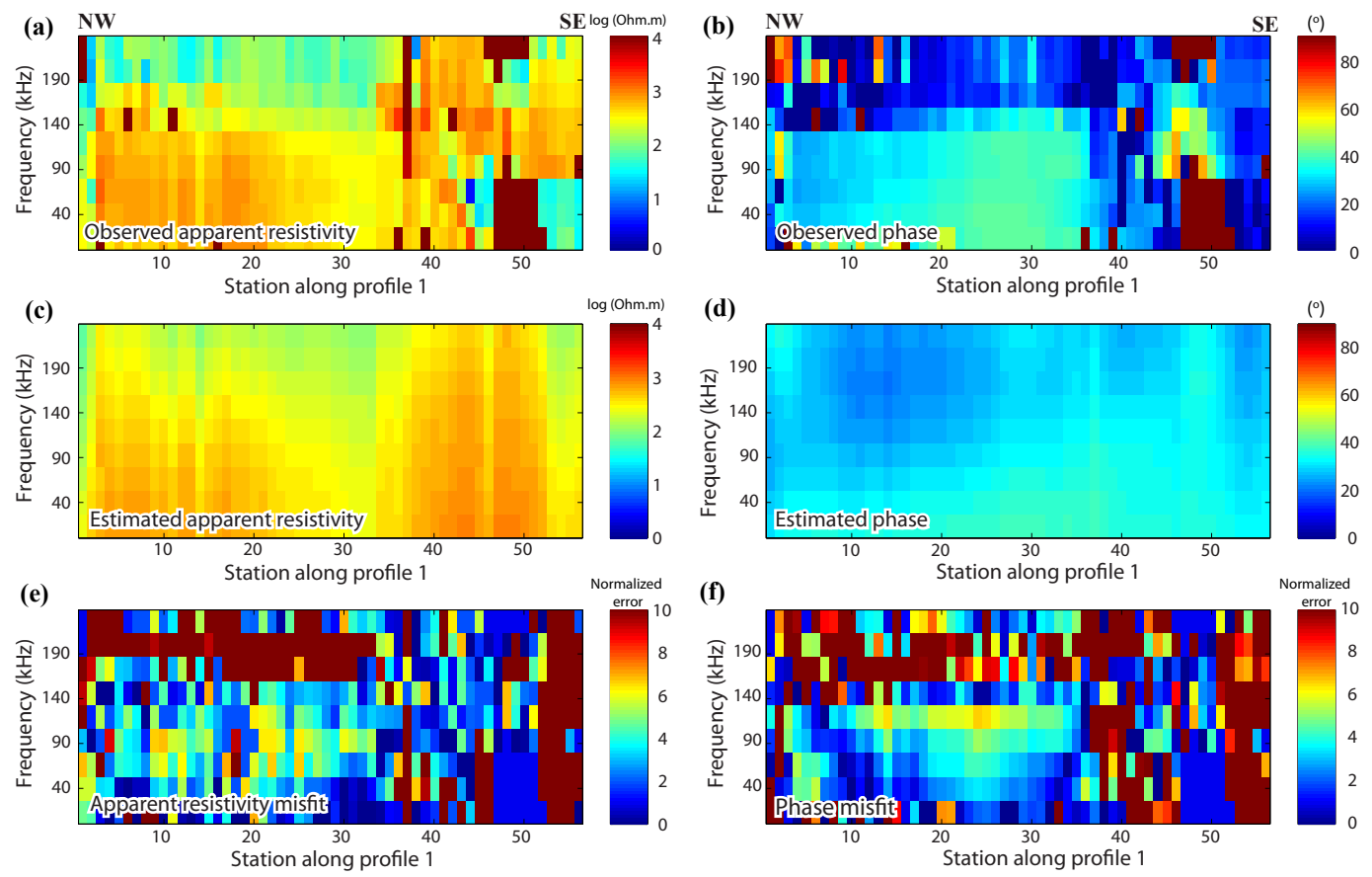

Figure 9. Observed (a) apparent resistivity and (b) phase plots for all the RMT frequencies measured along the stations of profile 1. Estimated (c) apparent resistivity and (d) phase plots and their (e-f) corresponding normalized misfits. In general RMT data quality is good and some structures in the raw data can already be observed.

more sensitive to resistive targets. Typically, a four-electrode array (electrode spread) is employed, where two electrodes are used to induce the electrical current into the ground (current electrodes), and the remaining two are used to measure the resulting potential difference (Loke, 2014).

In our study, we used the ABEM Terameter ${ }^{\mathrm{TM}}$ LS. Both profiles were acquired using the gradient array (Dahlin and Zhou, 2006) and an electrode spacing of $5 \mathrm{~m}$. The advantage of this array type over the other arrays is higher penetration depth and lower degree of data loss at the edges of the survey lines (Dahlin and Zhou, 2006). Profile 1 was $400 \mathrm{~m}$ long, while profile 2 was $700 \mathrm{~m}$ long and required a rollalong (Günther, 2004) acquisition. We used $300 \mathrm{~m}$ overlap between the two consecutive segments, implying an increment of $100 \mathrm{~m}$ for the measurements. Figure 10a shows the apparent resistivity section obtained for the data along profile 1 . A clear indication of change in the resistivity structure around $200 \mathrm{~m}$ distance along the profile is notable.

Data inversion was carried out using DC2DInvRes (Günther, 2004; Günther and Rücker, 2006a, b). The inversion was done incorporating topography for both lines with horizontal grid spacing of $5 \mathrm{~m}$ and vertical grid spacing of $2.5 \mathrm{~m}$. The final models used for the interpretation had RMS errors of 4.8 and 4.2 for profiles 1 and 2 respectively. Figure 10b shows the data misfit section along profile 1 , suggesting a relatively good fit to the data.

\subsection{GPR and geodetic surveys}

Electromagnetic waves used in the GPR method can be reflected by geological interfaces such as sediment/crystalline basement interface or syn-sediment features (e.g. Dehls et al., 2000; Reynolds 2011), provided that these interfaces coincide with discontinuities in the electrical and dielectric properties. GPR investigations, were therefore justified in the Bollnäs case to tentatively help delineate the top of the basement or the inner structure of the sediments. Two $100 \mathrm{MHz}$ antennas, separated by $1 \mathrm{~m}$, one acting as transmitter and another as receiver were used for the data acquisition. Uniform sampling along the profile was ensured by using a thread pulled along with the acquisition system as a trigger. Several GPR profiles were measured, either at high angle or subparallel to the scarp (Fig. 3). Only moderate data processing was applied to the data. This included amplitude gaining of the data to increase the visibility of features at depth and to avoid short-time ringing artefacts due to unshielded antenna and non-zero distance between the antenna and ground. The drift of the traces, which was amplified by this procedure were then removed using a high-pass filter. To convert time to depth, a homogeneous velocity of $0.4 \times 10^{8} \mathrm{~m} \mathrm{~s}^{-1}$ was used based on the experience from other studies (e.g. Bradford, 2010).

Geodetic positioning of all the stations for all the different surveys was carried out using a DGPS system (Fig. 4b) with precision of a few centimetres both horizontally and verti- 

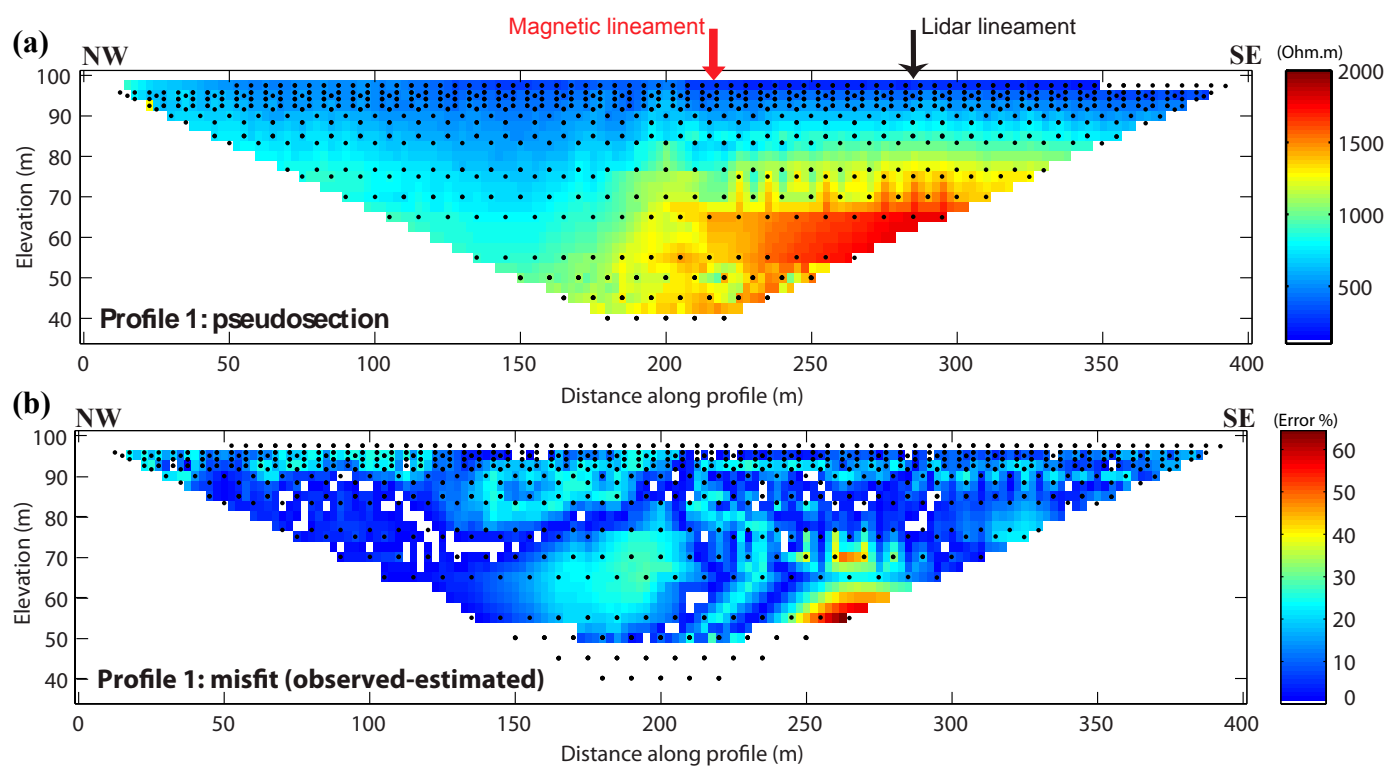

Figure 10. (a) Apparent resistivity (pseudosection section) and (b) misfit sections (normalized observed minus estimated) of the ERT data along profile 1 clearly showing the presence of a major resistive body on the eastern side of the scarp and sudden change in its appearance at $200 \mathrm{~m}$ distance along the profile.

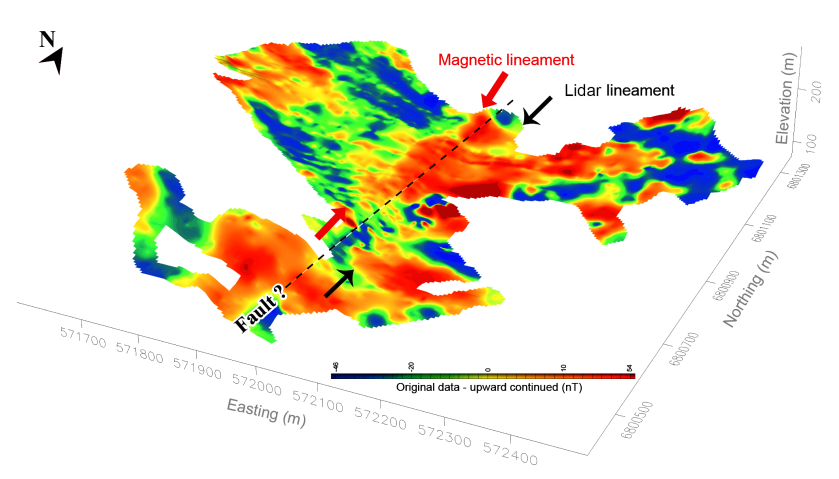

Figure 11. Upward continued for $20 \mathrm{~m}$ and then subtracted from the measured total-field magnetic data and projected onto the lidar data (Fig. 3). The magnetic lineament about 50-60 m west of the scarp is slightly enhanced and the footprint of the measurements is reduced. We attribute the magnetic lineament to a basement high in the eastern side of the scarp somewhere at halfway between the magnetic lineament and the lidar lineament (see the black dashed line). This could be the actual location of a basement fault forming the Bollnäs scarp (see also Fig. 2b) or it could be solely due to the elevation difference in the bedrock.

cally. The GPS signal was excellent due to the open space with no dense tree coverage. Magnetometry data collected in the forest areas still showed a good-quality GPS signal.

\section{Results and interpretations}

Before we present the results, in the following we define the bedrock depth as the vertical distance between the top of the bedrock and the surface (given in negative values), and the bedrock level as compared to the real topography i.e. sea level (given in positive values).

To enhance the short wavelength pattern observed on the total field magnetic data, we subtracted from the data the $20 \mathrm{~m}$ upward continued total field and projected the residual onto the lidar data (Fig. 11). This clearly depicts a magnetic lineament (defined as horizontal gradient maxima) about 50 $60 \mathrm{~m}$ west of the scarp, suggesting a sharp change in the bedrock depth or nature at this location. This is consistent with the large-scale airborne magnetic data from the study area (Fig. 2b). Tests with reduction to the magnetic pole did not significantly move the location of the magnetic lineament because of the high geographic latitude of the study area (earth's magnetic field is nearly vertical). The magnitude of the total magnetic field, while showing local variations, is in general higher on the eastern side of the scarp than on the western side by nearly $200 \mathrm{nT}$. If we assume the magnetic response to be solely due to a crystalline bedrock that is magnetically uniform in our study area, this result suggests that the bedrock, contrary to our expectation, is at shallower depths on the eastern side of the scarp than on the western side. Alternatively, one can argue that there are more glacial and post-glacial sediments on the western side of the scarp forming the apparent topography in the study area.

We tested various possible densities for glacial and postglacial sediments (Salas-Romero et al., 2015) such as 1800 to $2200 \mathrm{~kg} \mathrm{~m}^{-3}$ as shown in Fig. 6a. Interestingly, densities around $2000 \mathrm{~kg} \mathrm{~m}^{-3}$ result in a complete Bouguer anomaly (Figs. 5b and 12b) that is nearly uniform (or only has a few gravity unit variations) on both sides of the scarp, particularly 

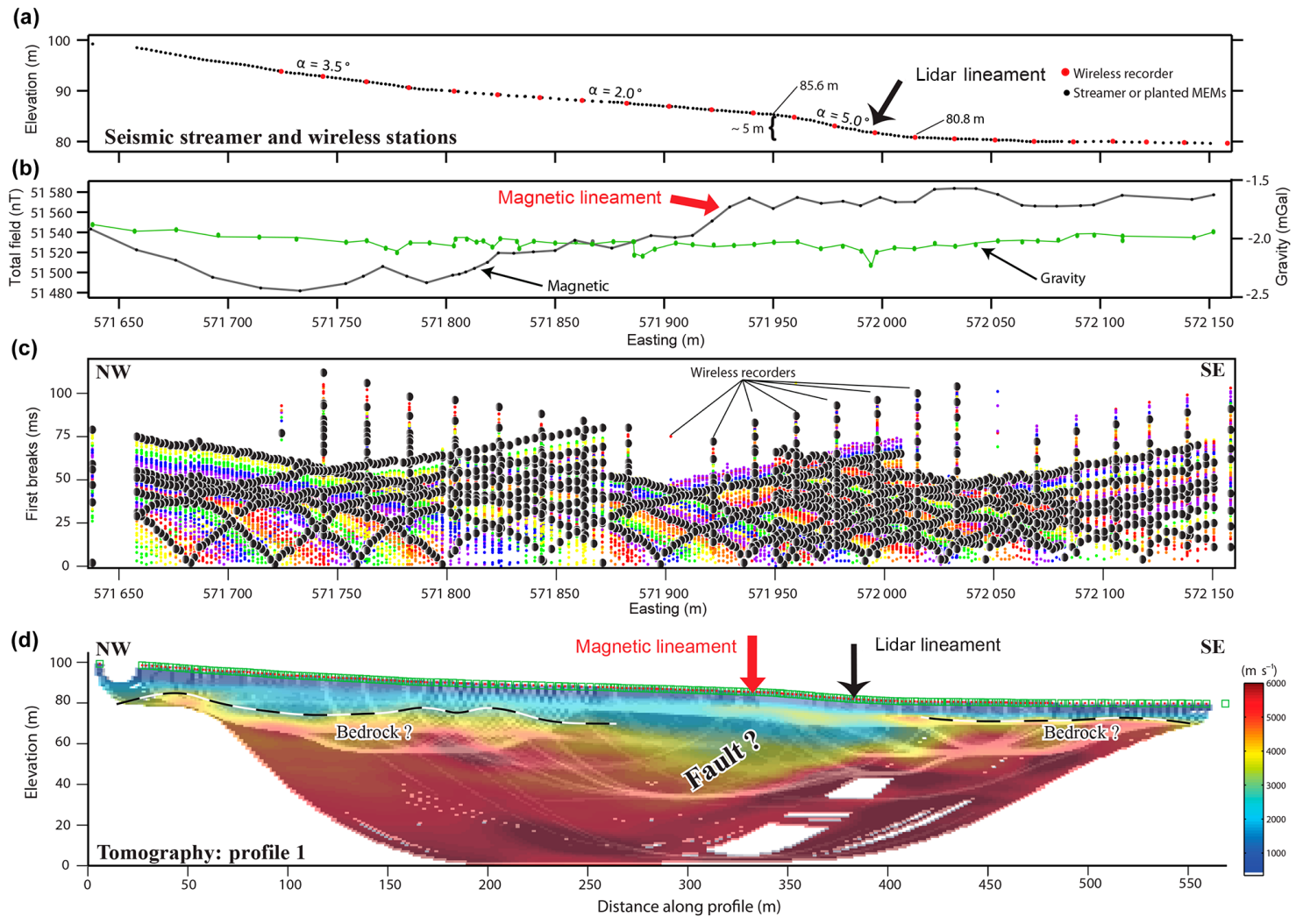

Figure 12. A compilation of (a) DGSP geodetic surveying of the seismic stations showing the general topography in the study area, (b) magnetic and gravity data, (c) first breaks used for the tomography and (d) tomographic model along profile 1 . Bedrock is shallower in the eastern side of the scarp as evident from the first breaks. Ray density is overlaid on the tomographic section ranging from 1 to 3000 . Large offset first breaks are from the wireless recorders. The low velocity depression zone is likely to be associated with the Bollnäs scarp.

along profile 1 . This may suggest that there is no detectable bedrock level difference from one side of the scarp to another or simply that the gravity measurements have no resolution to resolve such a small change. We will discuss this in detail later.

Tomography results (Fig. 12d) indicate two major results. Firstly, a major low-velocity zone is delineated at the scarp location and slightly towards the west of it along profile 1 . It is likely due to a zone of highly fractured rocks or a depression in the bedrock that is filled with glacial and postglacial sediments. Secondly, an indication that the bedrock is at an elevation of about $80 \mathrm{~m}$ on both sides of the scarps and therefore, due to topography, the cover sediments are thicker on the western side of the scarp as suggested by gravity and magnetic data (Fig. 12b).

Interestingly, RMT results along both profiles (Fig. 13) consistently show a major high conductivity zone apparently dipping slightly west of the scarp. We believe the conductive anomaly represents a major water-bearing zone, with a porosity related to a brittle deformation zone in the bedrock. The top of the bedrock is also somewhat resolved but not as well as the conductor. It is not possible to clearly estimate any throw and displacement in the bedrock from the
RMT data either. Nevertheless, it is possible to infer thicker sediment cover on the western side of the scarp than on the eastern side, particularly along profile 2 (Fig. 13b).

ERT data are much more sensitive to resistive materials and thus should be able to better resolve the top of the bedrock. Unfortunately the ERT line along profile 1 is shorter than along profile 2 . Nevertheless, the bedrock surface and a major conductivity zone west of the scarp are also consistently evident in the ERT results (Fig. 14). Similar to the RMT results, ERT results also suggest the bedrock surface at more or less the same level. Hence it is difficult to estimate fault throw from these data as well. It is not likely to be higher than five metres based on the data from the south-eastern side of profile 2 (Fig. 14b).

In most of the GPR profiles, a shallow $\left(2-5^{\circ}\right)$ easterly dipping reflection between -3 to $-6 \mathrm{~m}$ depth was observed immediately east of the scarp (Fig. 15a). The GPR-depth penetration is quite restricted in the area, presumably as a consequence of the high clay content of the sediments. We believe GPR data do not provide any information from the bedrock and the reflection observed is likely to occur within the glacial sediments overlying the crystalline basement. Changing the velocity used for time-to-depth conver- 

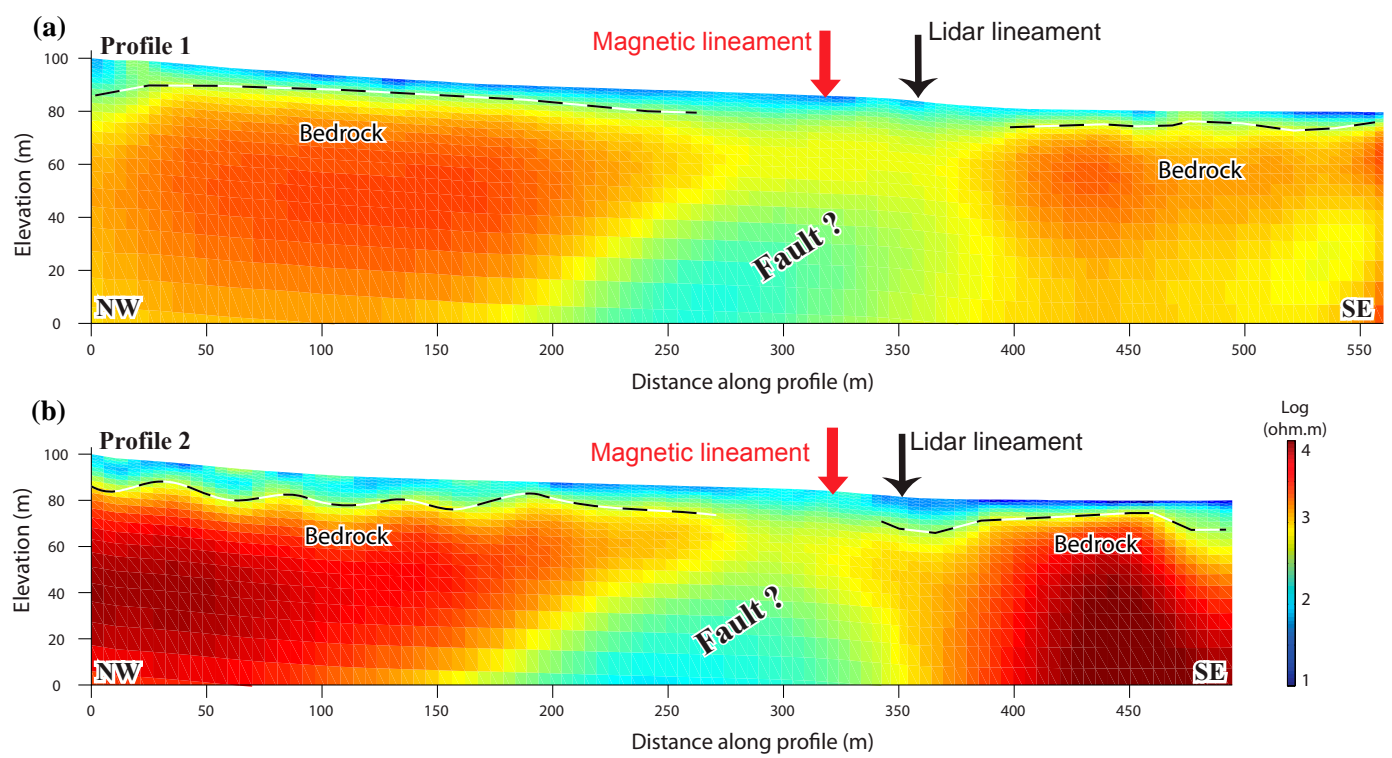

Figure 13. RMT results along (a) profile 1 and (b) profile 2 consistently showing clear evidence of a conductivity structure west of the scarp and in the bedrock. They also suggest that the bedrock is likely to be shallower on the eastern side of the scarp than on its western side. We attribute the conductive zone to highly fractured and water-bearing bedrock and possibly an indication of a post-glacial fault related to the Bollnäs scarp.

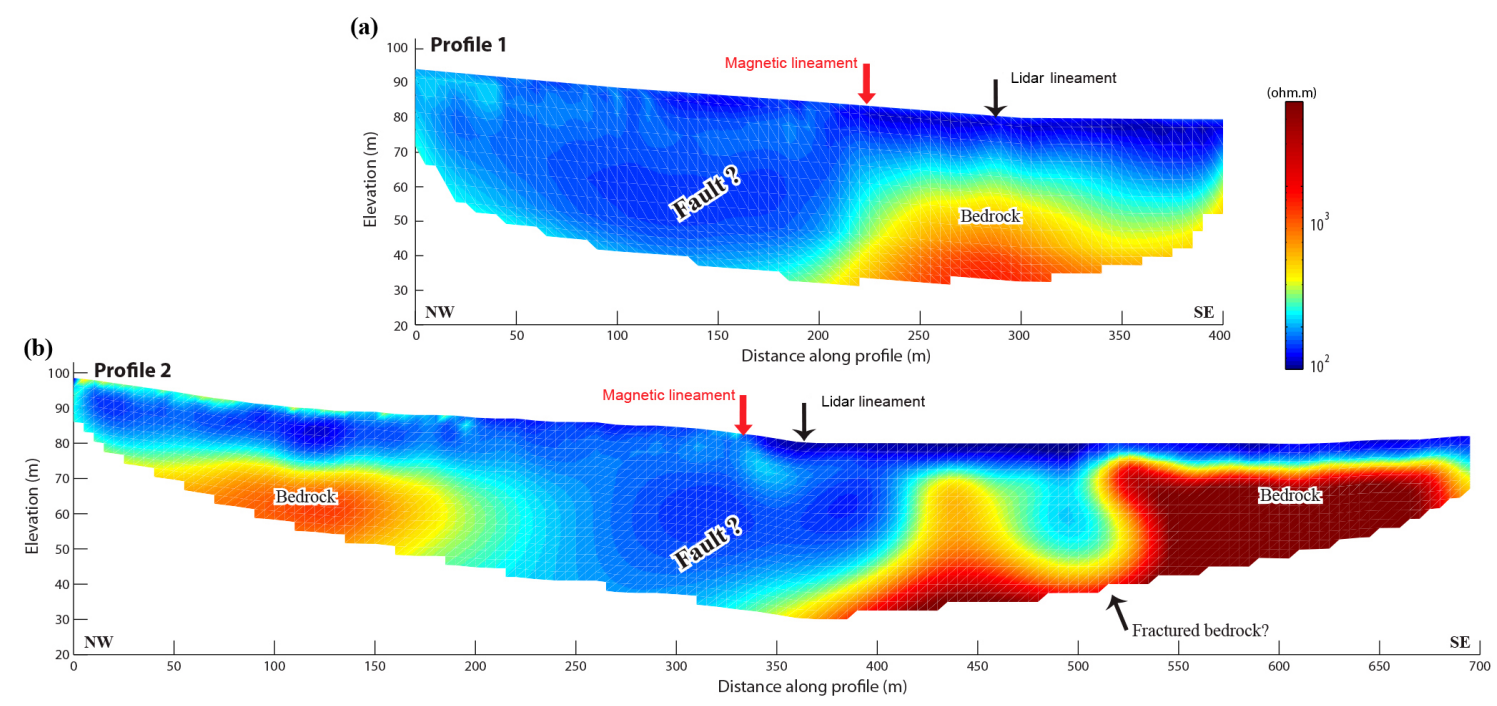

Figure 14. ERT results along (a) profile 1 and (b) profile 2 consistently showing clear evidence of a conductivity structure west of the scarp. They also suggest that the bedrock is shallower on the eastern side of the scarp than on its western side, consistent with the magnetic (Fig. 12), RMT (Fig. 13) and seismic results (Fig. 12).

sion would shift the reflector only a few metres either shallower or deeper. During the trenching at the site, Smith et al. (2014) noted a gently dipping $\left(3-5^{\circ}\right)$ till underlying silt and varved clays at depths around $-3 \mathrm{~m}$ (Fig. 15b, c). The reflection in the GPR data is likely to be generated at the contact between till and these materials. It is a common feature when the scarp is crossed up to about $300 \mathrm{~m}$ distance in the northern side of profile 1 . We observed this in more than five short GPR transects (blue points north of profile 2 in Fig. 3).
It is remarkable that we observe only one reflection in the GPR data and only on the eastern side of the scarp. It is possible that the lack of continuity in the western end of the GPR reflection, roughly where the scarp starts, is an indication for faulted sediments. Smith et al. (2014) reported a pronounced depression in the water-table surface along the scarp at one of the trenches they made in the northern parts of the study area. 


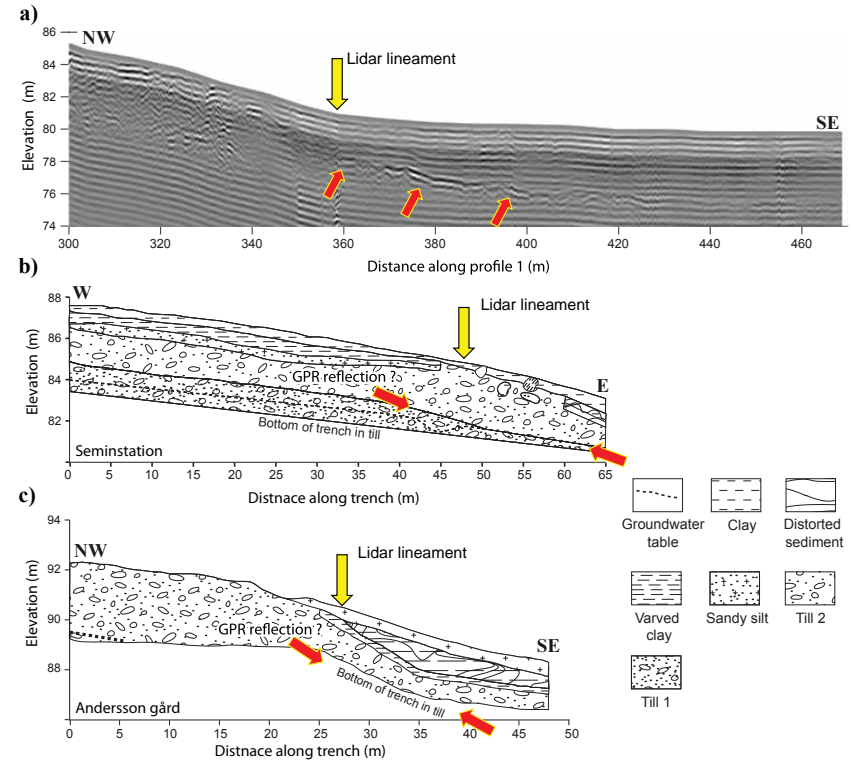

Figure 15. (a) Example of GPR profile recorded across the scarp exhibiting a gently dipping reflection immediately east of the scarp. This is interpreted as the base of the till (b) as observed in one of the trenches (seminstation in Fig. 3b) reported by Smith et al. (2014). It can also suggest a fault on its western end because the reflection disappears there. (c) The Andresson gård trench extends to the eastern side of the scarp, hence it is also used for a better comparison.

\section{Discussion}

The multiple geophysical methods used to study the Bollnäs scarp suggest a major structure in the bedrock about $20-30 \mathrm{~m}$ west of the lidar lineament. In order to illustrate the consistency among the different results, a 3-D visualization of all the results with surface geology and lidar data is shown in Fig. 16. Prior to discussing scenarios that can plausibly explain the scarp in light of the results and existing knowledge from available post-glacial faults, we first provide a simple synthesis of possible resolution of a few methods used in this study. It is important to note that in the absence of direct observations (i.e. boreholes), most of the discussion and interpretation of the geophysical data is speculative and may change as new data arrive from the site.

\subsection{Resolution issue: flat vs. stepped bedrock?}

The multiple geophysical methods employed in this study all point towards a complex situation where the bedrock step is either not resolvable or is small to nearly flat. At this stage, we favour the first scenario in which the bedrock is only offset by a couple of metres that is not resolvable by the methods employed. The difference in the cover sediments is the main challenge in this case. We do not, however, think that there is as much as a $5 \mathrm{~m}$ step in the bedrock (see McCalpin, 1996) nor that the bedrock is freshly faulted to allow it to clearly be resolved. It is possible that rocks at the fault zone are so fractured and mixed with the sediments that these together make the sediments on the western side of the scarp appear to be thicker than those on its eastern side.

To provide some insights about the possible contribution of the topography and different sediment thicknesses on each side of the scarp we carried out some simple gravity and magnetic modelling using the true topography of the study area and observed gravity and magnetic data. The modelling was performed using Model Vision ${ }^{\mathrm{TM}}$ (e.g. Malehmir et al., 2009) in 3-D although the model was kept 2-D by extending its lateral dimension to about $7500 \mathrm{~m}$. A step within otherwise flat topography was considered (Fig. 17). We assume the susceptibility in the till materials to be zero and that the magnetic signature is solely due to a magnetic bedrock. We used the density of $2000 \mathrm{~kg} \mathrm{~m}^{-3}$ for the till and $2700 \mathrm{~kg} \mathrm{~m}^{-3}$ for the bedrock. The forward response was calculated and compared with the observed data (a constant regional field, DC shift, had to be applied for the matching). It is striking to observe that gravity data have no sensitivity to the $5 \mathrm{~m}$ step and that the presence of shallow bedrock can also explain the magnetic data on the eastern side of the scarp. Introducing a $5 \mathrm{~m}$ step in the bedrock resulted in a magnetic minimum that we do not observe in the real data. This modelling further supports the idea of different sediment cover but no indication for the step in the bedrock.

To examine resolution capability of the tomographic method in resolving the possible step in the bedrock, we considered two simple scenarios: one in which the bedrock is flat and the other in which there is a $5 \mathrm{~m}$ step in the bedrock using the real geometry of profile 1. Travel times (Fig. 18a, b) were calculated using the forward finite-difference solver (Eikonal solver of Podvin and Lecomte, 1991) implemented in PStomo_eq code (Tryggvason et al., 2002) after manipulation of the model used to present the tomography results of the real data (Fig. 12). Velocities above the topography were set to $340 \mathrm{~m} \mathrm{~s}^{-1}$, and cover sediments (of varying thickness) were assigned a uniform velocity of $1800 \mathrm{~m} \mathrm{~s}^{-1}$ and bedrock $6000 \mathrm{~m} \mathrm{~s}^{-1}$ (Fig. 18c, d). The finite difference code is accurate (on the order of less than half a millisecond in our case) for first break travel time calculations of 3-D geometry data including non-planar topography. However, it uses a wide wave path (infinite frequency) assumption for this (Podvin and Lecomte, 1991). This means no frequency change (or wavelength) is expected at far offsets to influence the accuracy of the picks as the real data. Using the same starting model (Fig. 18e) and identical inversion parameters as used to invert the real data, we inverted for the corresponding velocity models of the synthetic first breaks (Fig. 18f, g). A careful inspection of the results suggests that a $5 \mathrm{~m}$ stepped bedrock would be resolved. However, we think this is too simple to represent a multi-phase deformation history of the Bollnäs fault and that a sharp/fresh bedrock transition is unlikely. Nevertheless, this is one way to illustrate that the tomography method works if permitted by the geology. We did 

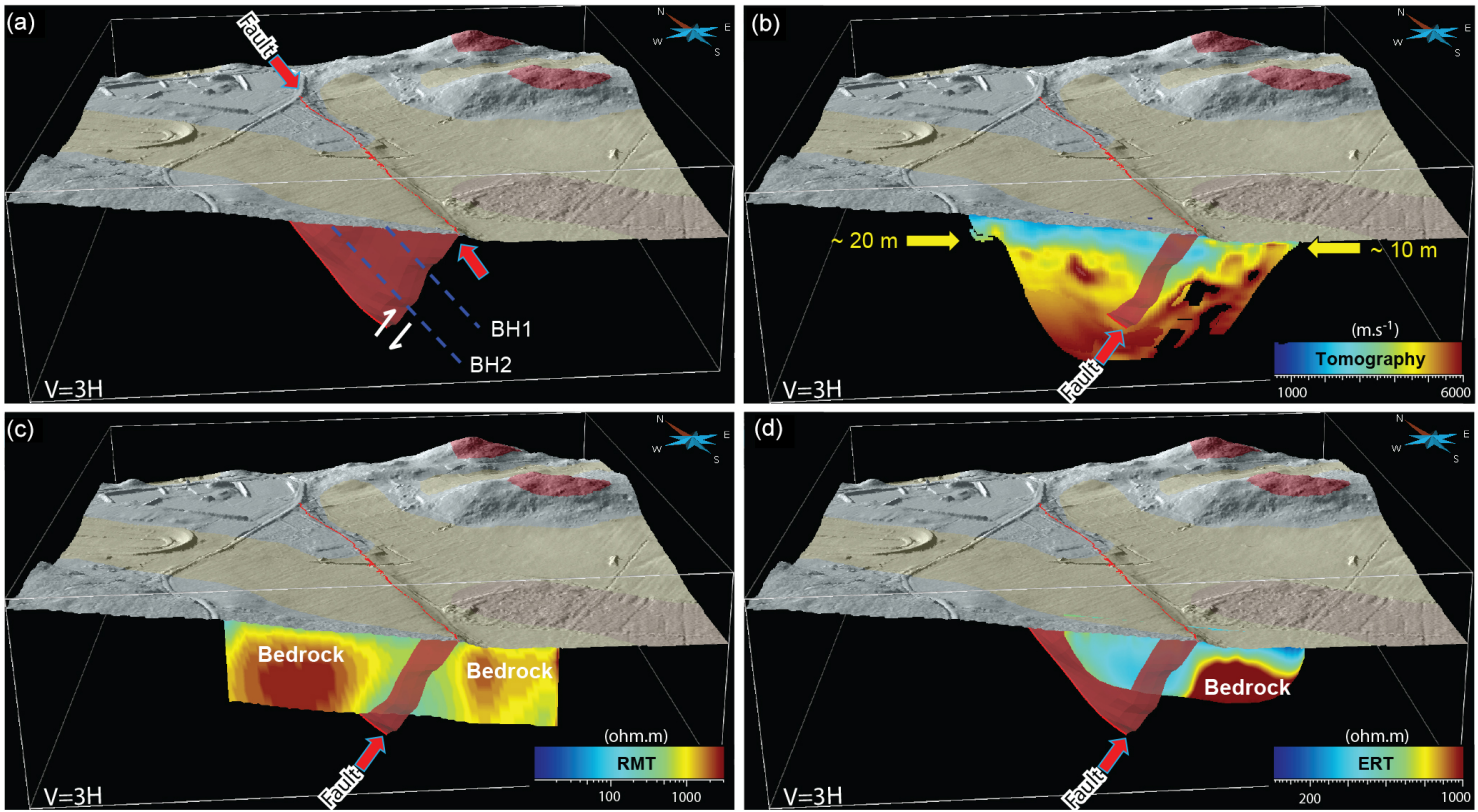

Figure 16. 3-D visualization of the geophysical results along profile 1. (a) Surface geology projected onto the lidar data with a hypothetical shape of the Bollnäs fault plane (assumed to be reversed) generated using the magnetic lineament observed in our own data, (b) travel time tomography, (c) RMT and (d) ERT models. Future plans should aim at drilling (e.g. BH1 and BH2) the weak zone that is interpreted to be a deformation zone hosting the Bollnäs postglacial fault and defining the bedrock level along profile 1. A better estimation of the throw may be then estimated and downhole logging would be conducted to verify the geophysical results presented here.
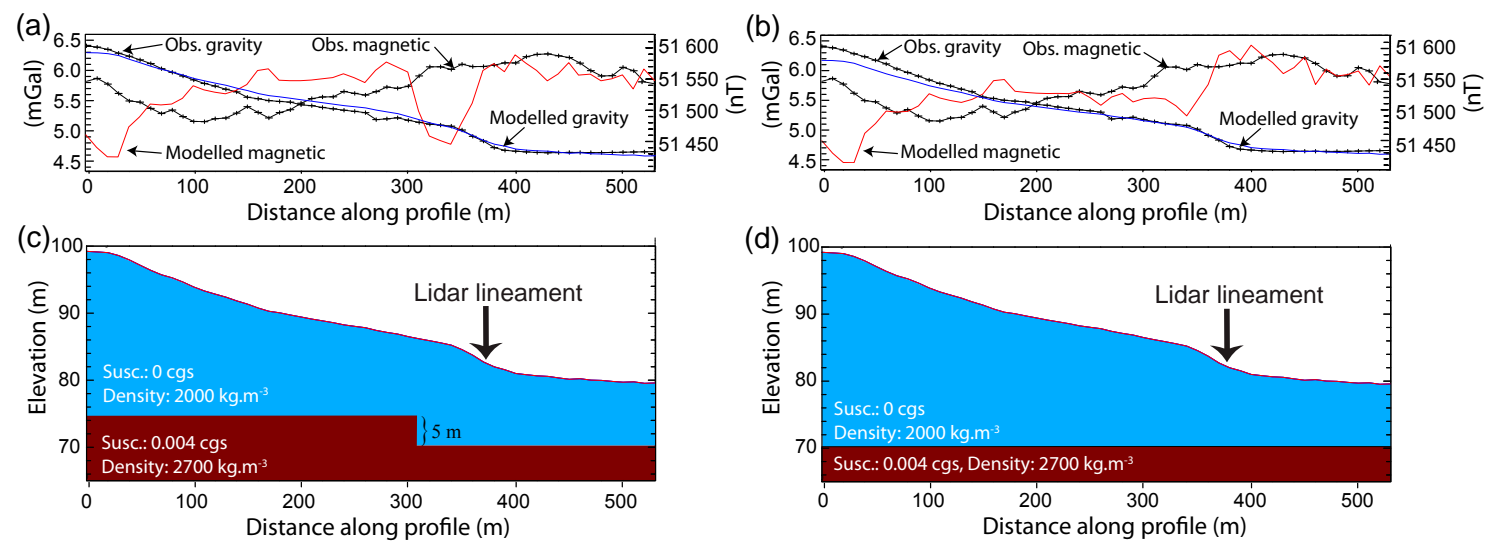

Figure 17. Forward modelling of gravity and magnetic data using two simple scenarios: (a, c) $5 \mathrm{~m}$ step or (b, d) flat bedrock. It is interesting to note that both observed magnetic and gravity data can be explained by the presence of different thickness cover materials and topography and that there is not so much sensitivity in the gravity data to a $5 \mathrm{~m}$ step. Magnetic data, however, show some sensitivity but the modelled response does not match the observed magnetic data. Short wavelength undulations are due to the high sensitivity of the model against topography (model not fully matching the surface topography) and can be ignored.

not consider conventional checkerboard tests or other scenarios such as perturbing the input data (e.g. Malehmir et al., 2015b) for the resolution test.

\subsection{Origin of the Bollnäs scarp and role of earlier structures}

One of the objectives of the study was to relate the Bollnäs scarp to features in the bedrock. We suggest that there is a relationship between the scarp and the high-conductivity and low-velocity structures observed in the bedrock from ERT, RMT and seismic data. There is a major brittle structure in 
the bedrock, causing the low-velocity and high-conductivity zone observed in these data. This can be linked to post-glacial fault movement forming the lidar lineament but it also points towards pre-existing structures. Magnetic lineaments, seismically anomalous and conductive zones have also been reported to be associated with topographic lineaments elsewhere in central Sweden (e.g. Malehmir et al., 2011); nevertheless interpreted to be associated with multi-phase deformation zones and not to any post-glacial faulting. It is difficult to explain why the bedrock is shallower on the eastern side of the scarp than on the western side if we expect the fault to be post-glacial and have recent reverse kinematics. It is unlikely that the Bollnäs scarp formed as a result of normal faulting (e.g. Dehls et al., 2000) because of the apparent surface morphology suggesting an upthrow on the western side and shallower bedrock on the eastern side.

To explain all the results, we relate the Bollnäs scarp to an earlier structure in the bedrock, likely a multi-phase deformation zone (Fig. 2) that acted as a normal fault much earlier (e.g. $>1.8 \mathrm{Ga}$ ). This means that the bedrock level was already at deeper levels on the western side of the scarp some time prior to the Weichselian deglaciation $(\sim 11000$ years ago). The erosion of older sediments and deposition of Weichselian glacial and post-glacial sediments resulted in thicker sediments on the western side of the scarp (Fig. 19). During deglaciation, the deformation zone was reactivated as a reverse fault triggered by the combination of tectonic and glacially induced stresses (Lund et al., 2015). Quaternary geologic data suggest a single rupture at about $10200 \mathrm{BP}$ (Smith et al., 2014).

The large-scale magnetic data (Fig. 2b) suggest that there are numerous magnetic lineaments in the study area, one of which is clearly associated with the Bollnäs scarp. We think these magnetic lineaments ( $\mathrm{N}-\mathrm{S}$ and $\mathrm{E}-\mathrm{W}$ trending) are evidence for pre-existing structures. Magnetic minima would then result from fluid circulation and alteration of magnetic minerals in these zones. Isaksson (2008) reported magnetic minima from deformation zones in central Sweden as a result of hematization of magnetite because of hydrothermal alteration.

The geophysical results suggest a moderately $\left(\sim 45^{\circ}\right)$ westward dip for the deformation zone (Fig. 16). Interestingly most post-glacial faults in northern Sweden show a throw opposite to what we infer for the Bollnäs fault. They are often down on the western side of the fault as opposed to the eastern side here. Again, this is likely to be controlled by pre-existing structures, illustrating their role in controlling the geometry and location of post-glacial faults in Sweden.

\subsection{Possible earthquake magnitude}

Assuming that the Bollnäs scarp is due to a post-glacial fault taking advantage of a pre-existing structure in the bedrock, we can only speculate on the magnitude of the associated earthquake(s) from some of the available data. We first as- sume that the Bollnäs scarp was formed as one event (Smith et al., 2014). Although we do not have evidence for it at this stage, the assumption is conservative from a safety assessment perspective (see also McCalpin, 1996). According to Stewart and Hancock (1990), a single piedmont scarp is likely to be the product of a single increment of motion when the scarp displays characteristic morphology comprising of a steep $\left(>50^{\circ}\right)$ free surface, a moderately inclined $\left(30-40^{\circ}\right)$ debris slope and a gently inclined $\left(5-10^{\circ}\right)$ washed slope. Some of these characteristics are consistent with the Bollnäs scarp (Fig. 12a) and may support our assumption.

Leonard (2010) points out that for dip-slip events in stable continental regions, the assumption that the surface rupture length is equal to the subsurface rupture length fits the data better than previously proposed relations between the two. We will therefore assume here that the total length of the scarp, $12 \mathrm{~km}$, equals the rupture length in the event. We further consider the $5 \mathrm{~m}$ high scarp as a proxy for the bedrock displacement that took place during the suspected earthquake. This is, however, a poorly constrained relation, which we discuss further below. Using the empirical equations of Leonard (2010) we estimate the possible magnitude of the Bollnäs event in two different ways. First using only the rupture length $(L)$ as input data and the equation (Leonard, 2010) we derive the following:

$\log \left(M_{0}\right)=2.5 \log (L)+8.08$,

with the usual relation between $M_{0}$ (scalar seismic moment) and $M_{w}$ (moment magnitude).

$M_{w}=2 \log \left(M_{0}\right) / 3-6.07$,

results in a magnitude $M_{w}=6.1$.

Secondly, we estimate the magnitude from the width $(W)$ of the fault plane (Leonard, 2010):

$W=13.5\left(L^{2 / 3}\right)$,

with that and the assumption that the height of the scarp equals the maximum slip in the event and that the average displacement $(D)$ is approximately half of the maximum displacement (Leonard, 2010), we can calculate the following:

$M_{0}=\mu \mathrm{WLD}$,

which results in a magnitude $M_{w}=6.5$ (using Eq. 2) for $\mu=33 \mathrm{GPa}$ (shear modulus; Leonard, 2010). We note that the Leonard (2010) regression for average displacement in a $12 \mathrm{~km}$ rupture length earthquake is only $0.67 \mathrm{~m}$. This could indicate that we significantly overestimate the average slip using the scarp height or underestimate the length of the fault. It is, however, in agreement with the observation by Muir-Wood (1989) that post-glacial earthquakes in northern Fennoscandia are short relative to their vertical offsets. With the data we have, we consider it likely that the Bollnäs scarp was created in a single large rupture; the associated magnitude would have probably been approximately $6-6.5$. 

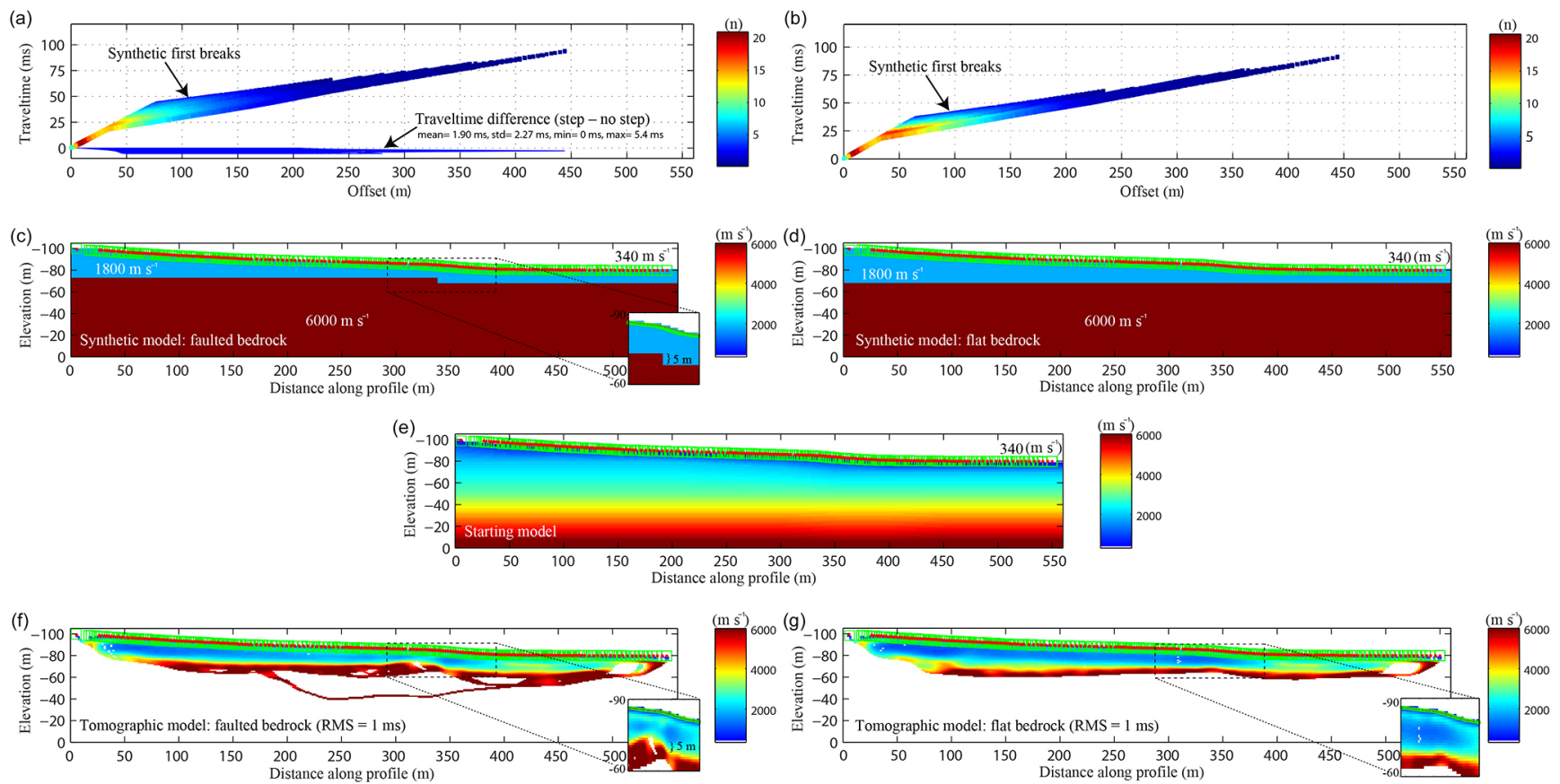

Figure 18. Synthetic first break travel times (a, b) calculated using two simple scenarios (c) faulted vs. (c) flat bedrock surfaces and based on the real geometry of the shot and receivers along profile 1. (e) The same starting model as used to invert the real first breaks was used to invert for the synthetic first breaks; corresponding models are shown in (f, g). While the rapid topography change is slightly disturbing the tomograms, it is still possible to infer a step in the bedrock if this is on the order of $5 \mathrm{~m}$ and higher and fresh bedrock on either sides. See text for detailed discussion.

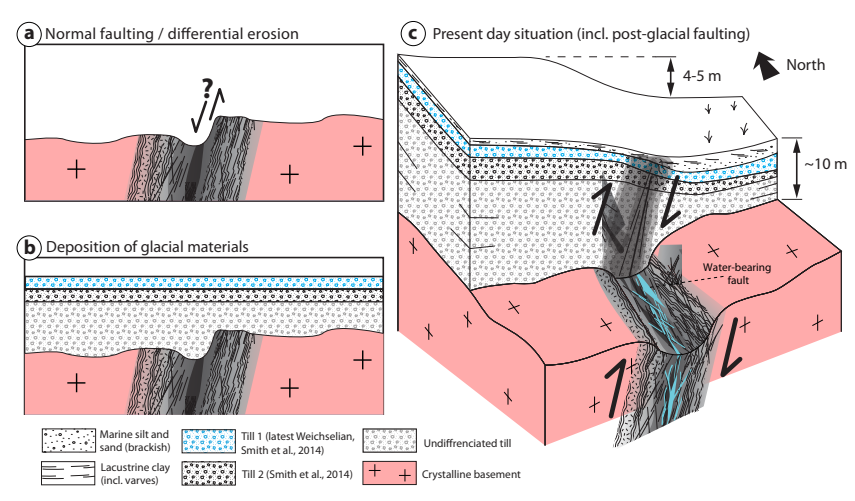

Figure 19. Schematic scenarios explaining the Bollnäs scarp and our interpretation of the geophysical results. (a) A damage zone inherited from brittle deformation events overprints earlier ductile deformation structures (Svecokarelian basement). (b) A varying thickness of till sequence covers the basement, which is thought to be deeper on the western side of the scarp than on the eastern side prior to the Weichsel glaciation. (c) The scarp is related to a recent (10200 BP; Smith et al., 2014) reversed fault in the basement that is water bearing (in blue). Top basement shows little to no obvious offset. Deformation patterns affecting the glacial deposits (e.g. water-escaped features) reported in Smith et al. (2014) are not detailed here.

\subsection{Future studies}

To prove that there is actually a post-glacial fault in the bedrock causing the Bollnäs scarp, a shallow drilling programme should be carried out. A couple of 50-100 m deep inclined holes (Fig. 16a) would be required to pass through the crushed rocks until fresh bedrock east of the scarp is observed. Locating the actual post-glacial fault plane may be difficult to impossible if only visual inspection of the core samples is used because of its interpreted multi-stage deformation nature. Therefore, a careful sampling and analysis of clay mineralogy and possibly age would be required to show that the crushed zone in fact hosts a post-glacial fault. More attention can also be given to the glacial sediments above the bedrock and, if possible, undisturbed samples (e.g. SalasRomero et al., 2015) from these sediments can be taken for detailed studies of changes in the stratigraphy due to the postglacial faulting.

Additionally, to observe the extent of the fault depth, a longer seismic profile similar to that carried out by Juhlin et al. (2010), also in conjunction with magnetotellurics methods, is recommended. Recently hydroacoustic and marine seismic data aiming at tracing the Bollnäs scarp across the lake Voxsjön (Fig. 2a) were acquired. Results are not available yet. We further suggest geophysical studies such as boattowed RMT (Bastani et al., 2015) to provide information 
about the depth to the bedrock on both sides of the scarp in the lake. Given the fresh nature of the water in the lake, RMT data acquisition is possible. Joint inversion of multiple data sets (e.g. Bastani et al., 2012) can also be performed, although we do not believe these can resolve the bedrock offset, since the bedrock is likely to be highly fractured and has no sharp surface to be resolved.

\section{Conclusions}

Several different surface geophysical methods were utilized to better understand the relationship between the Bollnäs scarp and potential structures in the bedrock. The Bollnäs scarp was found to be associated with a magnetic lineament, a major low-velocity and high-conductivity zone in the bedrock, hence interpreted to be associated with a fault. Despite a noticeable 4-5 m topographic high on the western side of the scarp, the geophysical results suggested more or less similar bedrock levels on both sides, with the only difference being thicker sediment cover on the western side than on the eastern side. The thicker sediment on the western side can explain the gravity and magnetic lows on the same side, supporting the interpretation that a bedrock step as little as a few metres cannot be resolved by the methods. The Bollnäs scarp is associated with a pre-existing structure i.e. a multi-phase deformation zone in the bedrock that was interpreted, at some stage, to have acted as a normal fault, allowing thicker deposition of glacial and post-glacial sediments prior to the postglacial faulting forming the lidar lineament in the study area. The location and geometry of the Bollnäs fault is interpreted to be solely controlled by this deformation zone. Based on the new finding for the length of the scarp and a series of assumptions, we estimate that the Bollnäs scarp was generated by a magnitude 6-6.5 earthquake in a single event.

Acknowledgements. Swedish Nuclear Fuel and Waste Management Company (SKB), Formas through Trusts 2.2 project (http://trust-geoinfra.se), Geophysics Program of Uppsala University and Geological Survey of Sweden provided partial funding and support to carry this study. Several MSc and PhD students as well as field teachers took part in the data acquisition and preparation of the data during the applied and exploration geophysics course (October 2014) for which we are grateful. GLOBE Claritas ${ }^{\mathrm{TM}}$ under license from the Institute of Geological and Nuclear Sciences Limited, Lower Hutt, New Zealand was used to process the seismic data. Refraction tomography was carried out using the 3-D PStomo_eq code (provided by Ari Tryggvason), RMT inversion using EMILIA (provided by Thomas Kalscheuer) and ERT inversion using DC2DInvRes (provided by Thomas Günther). gOcad $^{\mathrm{TM}}$ consortium and Paradigm are thanked for providing an academic license of $\mathrm{gOcad}^{\mathrm{TM}}$ for 3-D visualization and interpretation of the data. GMT from P. Wessel and W. H. F. Smith, Matlab and $\mathrm{gOcad}^{\mathrm{TM}}$ were used to prepare some of the figures. We thank E. A. Armadillo and an anonymous reviewer as well as the editor for their critical comments that helped to improve an early version of this manuscript.

Edited by: F. Rossetti

\section{References}

Ahmadi, O., Juhlin, C., Ask, M., and Lund, B.: Revealing the deeper structure of the end-glacial Pärvie fault system in northern Sweden by seismic reflection profiling, Solid Earth, 6, 621-632, doi:10.5194/se-6-621-2015, 2015.

Albrecht, L. and Kübler, L.: Bedrock Map 15G Bollnäs, scale $1: 250000$, Geological Survey of Sweden, K312, 2011.

Arvidsson, R.: Fennoscandian earthquakes: whole crustal rupturing related to postglacial rebound, Science, 274, 744-746, 1996.

Bastani, M.: EnviroMT- A New Controlled Source/Radio Magnetotelluric System, PhD thesis, Acta Universitatis Upsaliensis, Uppsala Dissertations from the Faculty of Science and Technology 32, 2001.

Bastani, M., Malehmir, A., Ismail, N., Pedersen, L. B., and Hedjazi, F.: Delineating hydrothermal stockwork copper deposits using controlled-source and radio-magnetotelluric methods: A case study from northeast Iran, Geophysics, 74, B167-B181, 2009.

Bastani, M., Savvaidis, A, Pedersen, L. B., and Kalscheuer, T.: CSRMT measurements in the frequency range of $1-250 \mathrm{kHz}$ to map a normal fault in the Volvi basin, Greece, J. Appl. Geophys., 75, 180-195, doi:10.1016/j.jappgeo.2011.07.001, 2011.

Bastani, M., Hübert J., Kalscheuer T., Pedersen L. B., Godio A., and Bernard J.: 2-D joint inversion of RMT and ERT data vs. individual 3-D inversion of full tensor RMT data: An example from Trecate site in Italy, Geophysics, 77, WB233-WB243, doi:10.1190/GEO2011-0525.1, 2012.

Bastani, M., Persson, L., Mehta, S., and Malehmir, A.: Boat-towed radio-magnetotellurics (RMT) - A new technique and case study from the city of Stockholm, Geophysics, 80, B193-B202, 2015.

Benz, H. M., Chouet, B. A., Dawson P. B., Lahr, J. C., Page, R. A., and Hole, J. A.: Three dimensional P- and S-wave velocity structure of Re- doubt volcano, Alaska, J. Geophys. Res., 101, 8111-8128, 1996.

Björck, S.: A review of the history of the Baltic Sea, 13.0-8.0 ka BP, Quaternary Int., 27, 19-40, 1995.

Bödvarsson, R. and Lund, B.: The SIL seismological data acquisition system -as operated in Iceland and in Sweden, in: Methods and applications of signal processing in seismic network operations, edited by: Takanami, T. and Kitagawa, G., Lecture Notes in Earth Sciences 98, Springer, Berlin, 2003.

Bradford, J. H.: Integrated hydrostratigraphic interpretation of 3D seismic-reflection and multifold pseudo-3-D GPR data, in: Advances in Near-surface Seismology and Ground-penetrating Radar, edited by: Miller, R. D., Bradford, J. H., and Holliger, K., Geophysical Developments Series, SEG, Tusla, USA, 15, 313326, 2010.

Brandes, C., Winsemann, J., Roskosch, J., Meinsen, J., Tanner, D.C., Frechen, M., Steffen, H., and Wu, P.: Activity of the Osning thrust during the late Weichselian: Ice-sheet and lithosphere interactions, Quaternary Sci. Rev., 38, 49-62, doi:10.1016/j.quascirev.2012.01.021, 2012. 
Brandes, C., Steffen, H., Steffen, R., and Wu, P.: Intraplate seismicity in northern Central Europe is induced by the last glaciation, Geology, 43, 611-614, 2015.

Brodic, B., Malehmir, A., Juhlin, C., Dynesius, L., Bastani, M., and Palm, H.: Multicomponent broadband digital-based seismic landstreamer for near surface applications, J. Appl. Geophys., 123, 227-241, 2015.

Dahlin, T. and Zhou, B.: Multiple-gradient array measurements for multichannel 2-D resistivity imaging, Near Surface Geophysics, 4, 113-123, 2006.

Dehls, J. F., Olesen, O., Olsen, L., and Blikra, L. H: Neotectonic faulting in northern Norway; the Stuoragurra and Nordmannvikdalen post-glacial faults, Quaternary Sci. Rev., 19, 14471460, 2000.

Günther, T: Inversion methods and Resolution Analysis for the 2D/3-D Reconstruction of Resistivity Structures from DC measurements, $\mathrm{PhD}$ thesis, University of Mining and Technology, Freiberg, 2004.

Günther, T. and Rücker, C.: A general approach for introducing information into inversion and examples from dc resistivity inversion, EAGE Near Surface Geophysics, Helsinki, Finland, 2006a.

Günther, T. and Rücker, C.: A new joint inversion approach applied to the combined tomography of dc resistivity and seismic refraction data, 19th Symposium on the Application of Geophysics to Engineering and Environmental Problems (SAGEEP 2006), Seattle, USA, 2-6 April, 2006b.

Isaksson, H.: Magnetic lineaments and their relationship to ductile structures and steeply dipping fracture zones at Forsmark, Fennoscandian Shield, Sweden, International Geological Congress, Oslo, available at: http://www.cprm.gov.br/33IGC/ 1316395.html (last access: 7 October 2015), 2008.

Jakobsson, M., Björck, S., O’Regan, M., Flodén, T., Greenwood, S.L., Swärd, H., Lif, A., Ampel, L., Koyi, H., and Skelton, A.: Major earthquake at the Pleistocene-Holocene transition in Lake Vättern, southern Sweden, Geology, 42, 379-382, 2014.

Juhlin, C. and Lund, B.: Reflection seismic studies over the endglacial Burträsk fault, SkellefteÅ, Sweden, Solid Earth, 2, 9-16, doi:10.5194/se-2-9-2011, 2011.

Juhlin, C., Dehghannejad, M., Lund, B., Malehmir, A., and Pratt, G.: Reflection seismic imaging of the end-glacial Pärvie fault system, northern Sweden, J. Appl. Geophys., 70, 307-316, 2010.

Hole, J. A.: Nonlinear high-resolution three-dimensional seismic traveltime tomography, J. Geophys. Res., 97, 6553-6562, 1992.

Hole, J. A. and Zelt, B.C.: 3-D finite-difference reflection traveltimes, Geophys. J. Int., 121, 427-434, 1995.

Kane, M. F.: A comprehensive system of terrain corrections using a digital computer, Geophysics, 27, 455-462, 1962.

Kalscheuer, T., Pedersen, L. B., and Siripunvaraporn, W.: Radiomagnetotelluric two-dimensional forward and inverse modelling accounting for displacement currents, Geophys. J. Int. 175, 486514,2008

Kuivamäki, A., Vuorela, P., and Paananen, K.: Indications of postglacial and recent bedrock movements in Finland and Russian Karelia, Geolological Survey of Finland, Helsinki, Finland, Report YST-99, 1998.

Lagerbäck, R. and Sundh, M.: Early Holocene faulting and paleoseismicity in northern Sweden, Tech. Rep. C836, Geological Survey of Sweden, Uppsala, Sweden, 2008.
Leonard, M.: Earthquake fault scaling: self-consistent relating of rupture length, width, average displacement, and moment release, B. Seismol. Soc. Am., 100, 1971-1988, 2010.

Lindblom, E., Lund, B., Tryggvason, A., Uski, M., Bödvarsson, R., Juhlin, C., and Roberts R.: Micro-earthquakes illuminate the deep structure of the end-glacial Pärvie fault, northern Sweden, Geophys. J. Int., 201, 1704-1716, 2015.

Loke, M. H.: Electrical resistivity surveys and data interpretation, in: Solid Earth Geophysics Encyclopedia, 2nd Edn. "Electrical and Electromagnetic", edited by: Gupta, H., SpringerVerlag, the Netherlands, 276-283, 2014.

Lund, B.: Palaeoseismology of glaciated terrain, Springer Encyclopedia of Earthquake Engineering, Springer, Berlin, doi:10.1007/978-3-642-36197-5_25-1, 2015.

Lund, B., Schmidt, P., and Hieronymous, C.: Stress evolution and fault stability during the Weichselian glacial cycle, Tech. Rep. TR-09-15, Swedish Nuclear Fuel and Waste Management Co. (SKB), Stockholm, Sweden, available at: www.skb.se/ publications, last access: 26 March 2015.

Malehmir, A., Thunehed, H., and Tryggvason A.: The Paleoproterozoic Kristineberg mining area, northern Sweden?: Results from integrated 3-D geophysical and geologic modeling, and implications for targeting ore deposits, Geophysics, 74, B9-B22, 2009.

Malehmir, A., Dahlin, P., Lundberg, E., Juhlin, C., Sjöström, H., and Högdahl, K.: Reflection seismic investigations in the Dannemora area, central Sweden: insights into the geometry of polyphase deformation zones and magnetite-skarn deposits, J. Geophys. Res., 116, B11307, 2011.

Malehmir, A., Wang, S., Lamminen, J., Brodic, B., Bastani, M., Vaittinen, K., Juhlin, C., and Place, J.: Delineating structures controlling sandstone-hosted base-metal deposits using highresolution multicomponent seismic and radio-magnetotelluric methods: a case study from Northern Sweden, Geophys. Prospect., 63, 774-797, doi:10.1111/1365-2478.12238, $2015 \mathrm{.}$.

Malehmir, A., Zhang, F., Dehgahnnejad, M., Lundberg, E., Döse, C., Friberg, O., Brodic, B., Place, J., Svensson, M., and Möller, H.: Planning of urban underground infrastructure using a broadband seismic landstreamer - Tomography results and uncertainty quantifications from a case study in southwest of Sweden, Geophysics, 80, B177-B192, 2015b.

McCalpin, J. P.: Paleoseismology, Academic Press, New York, USA, 1996.

Miller, H. G. and Singh, V. J.: Potential Field tilt - A new concept for location of potential field sources, J. Appl. Geophys. 32, 213-217, 1994.

Mikko, H., Smith, C. A, Lund, B., Ask, M., and Munier, R.: LiDAR-derived inventory of 25 post-glacial fault scarps in Sweden, J. Geol. Soc. Sweden, 137, 334-338, doi:10.1080/11035897.2015.1036360, 2015.

Mörner, N. A.: Active faults and paleoseismicity in Fennoscandia, especially Sweden, Primary structures and secondary effects, Tectonophysics, 380, 139-157, 2004.

Mörner, N.-A.: Paleoseismology: The application of multiple parameters in four case studies in Sweden, Quaternary Int., 242, 65-75, doi:10.1016/j.quaint.2011.03.054, 2011.

MuirWood, R.: Extraordinary deglaciation reverse faulting in northern Fennoscandia, in: Earthquakes at North-Atlantic Passive Margins: Neotectonics and Postglacial Rebound, edited by: 
Gregersen, S. and Basham, P. W., NATO ASI Series, Denmark, 141-173, 1989.

Olesen, O., Blikra, L. H., Braathen, A., Dehls, J. F., Olsen, L., Rise, L., Riis, F., Faleide, J. I., and Anda, E.: Neotectonic deformation in Norway and its implications: A review, Norw. J. Geol., 84, 3-34, 2004.

Olesen, O., Kierulf, H. P., Brönner, M., Dalsegg, E., Fredin, O., and Solbakk, T.: Deep weathering, neotectonics and strandflat formation in Nordland, northern Norway, Norw. J. Geol., 93, 189-213, 2013

Paasche, H. Characterization of alluvial aquifers using geophysical techniques: Integrated surveying strategies and case studies, Federal Institute of Technology Zurich, 2006.

Palmer, D.: Characterizing the near surface with detailed refraction attributes, in: Advances in Near-Surface Seismology and Ground-Penetrating Radar, edited by: Miller, R. D., Bradford, J. H., and Holliger, K., Geophysical Developments Series, SEG, Tusla, USA, 15, 233-249, 2010.

Pedersen, L. B. and Engels, M.: Routine 2-D inversion of Magnetotelluric data using the determinant of the impedance tensor, Geophysics, 70, G33-G41, 2005.

Pedersen, L. B., Bastani, M., and Dynesius L.: Some characteristics of the electromagnetic field from radio transmitters in Europe, Geophysics, 71, G279-G284, doi:10.1190/1.2349222, 2006.

Place, J. A. P., Malehmir, A., Högdahl, K., Juhlin, C., and Persson Nilsson, K.: Seismic characterization of the Grängesberg iron deposit and its mining-induced structures, central Sweden, Interpretation, 3, SY41-SY56, 2015.

Podvin, P. and Lecomte, I.: Finite difference computation of traveltimes in very contrasted velocity models: a massively parallel approach and its associated tools, Geophys. J. Int., 105, 271-284, 1991.

Reynolds, J. M.: An Introduction to Applied and Environmental Geophysics, 2nd Edn., Wiley, 25 Chichester, UK, ISBN:978-0471-48535-3, 2011.

Salas-Romero, S., Malehmir, A., Snowball, I., Lougheed, B. C., and Hellqvist, M.: Identifying landslide preconditions in Swedish quick clays - insights from integration of surface geophysical, core sample- and downhole-property measurements, Landslides, doi:10.1007/s10346-015-0633-y, online first, 2015.
Shan, C., Bastani, M., Malehmir, A., Persson, L., and Engdahl, M.: Integrated 2-D modelling and interpretation of geophysical and geotechnical data to delineate quick clays at a landslide site in southwest Sweden, Geophysics, 79, EN61-EN75, doi:10.1190/GEO2013-0201.1, 2014.

Siripunvaraporn, W. and Egbert, G.: An efficient data-subspace inversion method for two-dimensional magnetotelluric data, Geophysics, 65, 791-803, 2000.

Smith, C., Sundh, M., and Mikko, H.: Surficial geologic evidence for early Holocene faulting and seismicity, Int. J. Earth Sci., 103, 1711-1724, 2014.

Stewart, I. S. and Hancock, P. L.: Brecciation and fracturing within neotectonic normal fault zones in the Aegean region, in: Deformation Mechanisms, Rheology and Tectonics, edited by: Knipe, R. J. and Rutter, E. H., Geol. Soc. Spec. Publ., 54, 105-112, 1990.

Stummer, P., Maurer, H., and Green, A.G. Experimental design: Electrical resistivity data sets that provide optimum subsurface information, Geophysics, 69, 120-139, 2004.

SNSN: Earthquake locations, Swedish National Seismic Network, Uppsala University, Sweden, available at: www.snsn.se, last access: August 2015.

Sukotjo, S. and Sträng, T.: Bedrock Map 14G Ockelbo NO, scale $1: 50000$, Geological Survey of Sweden, Helsinki, Finland, K22, 2005.

Tryggvason, A. and Bergman, B.: A travel time reciprocity inaccuracy in the time $3 \mathrm{~d}$ finite difference algorithm by Podvin and Lecomte, Geophys. J. Int., 165, 432-435, 2006.

Tryggvason A., Rögnvaldsson, S. T., and Flovenz, Ó. G.: Three dimensional imaging of $\mathrm{P}$ - and $\mathrm{S}$-wave velocity structure and earthquake locations beneath southwest Iceland, Geophys. J. Int., 151, 848-866, 2002.

Wu, P., Johnston, P., and Lambeck, K.: Postglacial rebound and fault instability in Fennoscandia, Geophys. J. Int., 139, 657-670, 1999. 